
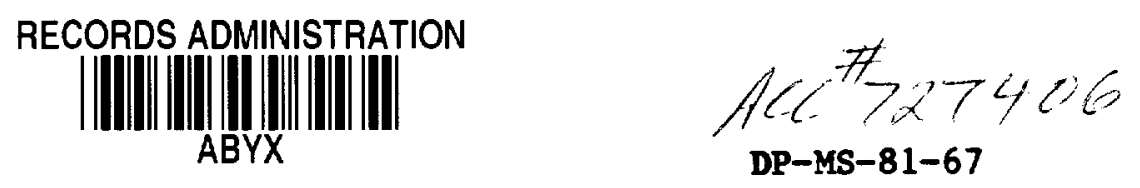

\title{
SUBCRITICAL LIMITS FOR ${ }^{233} \mathrm{U}$ SYSTEMS
}

by

Hugh. K. Clark

E. I. du Pont de Nemours \& Co.

Savannah River Laboratory

Aiken, South Carolina. 29808

Proposed for publication in

Nuclear Science \& Engineering

This paper was prepared in connection with work done under Contract No. DE-AC09-76SR00001 with the U.S. Department of Energy. By acceptance of this paper, the publisher and/or recipient acknowledges the U.S. Government's right to retain a nonexclusive, royalty-free license in and to any copyright covering this paper, along with the right to reproduce and to authorize others to reproduce all or part of the copyrighted paper. 
This document was prepared in conjunction with work accomplished under Contract No.

DE-AC09-76SR00001 with the U.S. Department of Energy.

\section{DISCLAIMER}

This report was prepared as an account of work sponsored by an agency of the United States Government. Neither the United States Government nor any agency thereof, nor any of their employees, makes any warranty, express or implied, or assumes any legal liability or responsibility for the accuracy, completeness, or usefulness of any information, apparatus, product or process disclosed, or represents that its use would not infringe privately owned rights. Reference herein to any specific commercial product, process or service by trade name, trademark, manufacturer, or otherwise does not necessarily constitute or imply its endorsement, recommendation, or favoring by the United States Government or any agency

thereof. The views and opinions of authors expressed herein do not necessarily state or reflect those of the United States Government or any agency thereof.

This report has been reproduced directly from the best available copy.

Available for sale to the public, in paper, from: U.S. Department of Commerce, National Technical Information Service, 5285 Port Royal Road, Springfield, VA 22161, phone: (800)

553-6847, fax: (703) 605-6900, email: orders@ntis.fedworld.gov online ordering: http://www.ntis.gov/ordering.htm

Available electronically at http://www.doe.gov/bridge

Available for a processing fee to U.S. Department of Energy and its contractors, in paper, from: U.S. Department of Energy, Office of Scientific and Technical Information, P.O. Box 62, Oak Ridge, TN 37831-0062, phone: (865 ) 576-8401, fax: (865) 576-5728, email: reports@ adonis.osti.gov 
DP-MS-81-67

\section{SUBCRITICAL LIMITS FOR ${ }^{233}$ O SYSTEMS}

by

Hugh. K. Clark

E. I. du Pont de Nemours \& Co . Savannah River Laboratory

Aiken, South Carolina 29808

\section{ABSTRACT}

As a contribution to the required quinquennial review of American National Standard for Nuclear Criticality Safety in Operations with Fissionable Materials Outside Reactors (ANSI N16.1-1975/ANS-8.1), limits for homogeneous ${ }^{233} \mathrm{U}$ systems have been recalculated to confirm their subcriticality or, where there were doubts, to propose more restrictive values. In addition, other limits were calculated to be proposed for inclusion, namely limits for aqueous solutions of $\mathrm{UO}_{2}\left(\mathrm{NO}_{3}\right)_{2}$ and limits for uranium oxides. The same three methods of calculation were used as in similar work done recently for plutonium and ${ }^{235} \mathrm{U}$ systems. The validity of each was established by correlation with the results of pertinent critical experiments. 


\section{INTRODUCTION}

In recent articles, 1,2 imits for plutonium systems and for ${ }^{235} \mathrm{U}$ systems were calculated for comparison with limits presently in American National Standard for Nuclear Criticality Safety in Operations with Fissionable Materials Outside Reactors. ${ }^{3}$ Where there was doubt as to subcriticality of limits in the Standard, more restrictive values were proposed. Occasionally, where the margin of subcriticality seemed unnecessarily large, slightly less restrictive values were proposed. Additional limits were proposed for inclusion in the Standard such as limits for oxides and for aqueous solutions of uranyl nitrate.

Part of the stimulus for this work was doubt expressed by McNeany and Jenkins ${ }^{4}$ as to the subcriticality of the dimensional limits for aqueous solutions of $233 \mathrm{U}$. Attention has now been turned to ${ }^{233} \mathrm{U}$ systems. The same three methods of calculation have been used as in the previous studies. All have been validated by comparison with pertinent critical (or nearly critical) experiments. Dimensional limits in the Standard have indeed been found to be too large, and more restrictive values are being proposed. Again, additional limits have been calculated, namely limits for aqueous solutions of uranyl nitrate and for uranium oxides, and are being proposed for inclusion in the Standard. 


\section{Calculational Methods}

The same three code combinations (MGBS-TGAN, HRXN-ANISN, and GLASS-ANISN) were used as in the previous correlations and 1 imit calculations. All codes are modules in the SRL JOSHUA system and are executed by the driver subsystem KOKO, which links the codes and facilitates the preparation of input. The codes MGBS, HRXN, and GLASS all serve the same function, the generation of problemdependent macroscopic cross sections from composition data and microscopic cross section libraries. MGBS collapses cross sections from a built-in 12-group library to two groups in a $\mathrm{B}_{0}$ spectrum for use in the two-group diffusion theory code TGAN. HRXN incorporates the 16-group Hansen-Roach 1 ibrary. GLASS collapses cross sections, taken from an 84-group library processed from ENDF/B-IV data, to 16 groups in a $B_{1}$ spectrum. ANISN performs $S_{n}$ transport theory calculations with either set of 16group cross sections. Reference 1 contains fuller descriptions of the methods.

No changes were made in how the codes were used, but a few remarks need to be made about MGBS. In Amster's compendium of thermal cross sections ${ }^{5}$, which is partially incorporated in MGBS, the thermal spectrum is a function of ${ }^{235} \mathrm{U} / \mathrm{H},{ }^{239} \mathrm{Pu} / \mathrm{H}, 1 / \mathrm{v}$ barns/H, and temperature. However, only cross sections for 0,2 , and 4 barns per hydrogen atom are incorporated in MGBS, although the compendium extends to 12 barns. In MGBS, ${ }^{233} \mathrm{U}$ is treated as a 
$1 / v$ absorber with regard to its effect on the spectrum. Threepoint Lagrangian interpolation and extrapolation is provided in terms of barns/H. Although cross sections change nearly linearly with barns/H, quadratic extrapolation to ratios as high as 17.5 (as in critical experiments with cylinders of aqueous solutions of $\mathrm{UO}_{2} \mathrm{~F}_{2}$ ) seems questionable. The ${ }^{233} \mathrm{U}$ absorption and fission cross sections deviate from strict $1 / v$ behavior; hence, relative thermal absorption may be in error at large extrapolations. On the other hand, as the spectrum hardens, the fraction of fission neutrons reaching the thermal group becomes small and the cross section errors may have little effect. However, at the high barns/H ratio of the volume and dimension limits ( $\sim 33$ for $\mathrm{UO}_{2} \mathrm{~F}_{2}$ solutions), MGBS-TGAN should probably be considered the least reliable of the three methods.

It should be noted that all three methods are onedimensional. An assumption of separability of the neutron flux into spatial components is required to extend them to finite cylinders or to cuboids. The schemes for doing this, implemented by SPBL for the two $S_{n}$ methods and by TGAN, are investigated in the Appendix.

\section{EXPERIMENTAL DATA}

Data for ${ }^{233} \mathrm{U}$ systems are much less extensive than for ${ }^{235} \mathrm{U}$ systems. No experiments have been done with a water-reflected sphere of ${ }^{233} \mathrm{U}$ metal. Experiments with solutions at the high concentrations at which minimum critical volumes and dimensions 
occur have not been done with spheres. For the one-dimensional computational methods being validated, the appropriate data are those obtained with spheres or with cylinders that can readily be extrapolated to critical diameters of cylinders with infinite height. Data obtained with vessels so large that assumptions of separability introduce 1 ittle uncertainty are also suitable. Experiments with solutions have been done with $\mathrm{UO}_{2} \mathrm{~F}_{2}$ and with $\mathrm{UO}_{2}\left(\mathrm{NO}_{3}\right)_{2}$ containing some free acid. Solution densities were calculated from the recipes used for ${ }^{235} \mathrm{U}$ solutions ${ }^{2}$ and from reported concentrations. Agreement with reported densities is good. However, calculated $\mathrm{UO}_{2}\left(\mathrm{NO}_{3}\right)_{2}$ solution densities are generally slightly greater than reported densities; $\mathrm{UO}_{2} \mathrm{~F}_{2}$ densities are slightly less.

\section{III.A Spheres of Aqueous Solution}

A series of experiments were done in 1953-1954 with two spherical vessels containing aqueous solutions of ${ }^{233} \mathrm{UO}_{2} \mathrm{~F}_{2}$ and having volumes of 9.66 and $17.02 \mathrm{~L}$ at room temperature. ${ }^{6}$ Both vessels were made critical, water-reflected, at several temperatures. The larger vessel was also made critical bare at a single temperature. The same two spheres were included in a series of experiments with $\mathrm{UO}_{2} \mathrm{~F}_{2}$ and $\mathrm{UO}_{2}\left(\mathrm{NO}_{3}\right)_{2}$ solutions apparently done at about the same time, but not reported until $1959 .{ }^{7,8}$ In the later report, the larger sphere is stated to have been coated internally with a polyvinyl chloride plastic, Unichrome, which is about 30 wt \% chlorine. Removal of the Unichrome was found to 
decrease the critical concentration of ${ }^{235} \mathrm{UO}_{2} \mathrm{~F}_{2}$ by $2 \%$. The Unichrome coating is apparently the systematic error, referred to in the earlier report, ${ }^{6}$ which resulted in masses and concentrations "believed to be about $2 \%$ high".

Other experiments with spheres include bare and waterreflected spheres of $\mathrm{UO}_{2}\left(\mathrm{NO}_{3}\right)_{2}$ solution ranging in volume from 5.8 to $26.0 \mathrm{~L} .9$ The spheres were made critical within \pm 0.0005 in $k_{\text {eff }}$. No free acid concentration is reported, but at 131 $\mathrm{g} \mathrm{U} / \mathrm{L}$ the solution averaged $0.375 \mathrm{M} \mathrm{HNO}_{3}$ (except for a bad value of $0.5 \mathrm{M}) .10$ The corresponding $\mathrm{N} / \mathrm{U}$ ratio is 2.67 , which presumably held at all uranium concentrations since the various concentrations were obtained by diluting the most concentrated solution.

Finally, experiments with uranyl nitrate solutions were performed in bare 174 and 949 1iter spheres. 11 In the smaller sphere, boron concentration was a variable. These experiments were later analyzed to obtain slight corrections for lack of sphericity, etc.12 with or without the corrections, the spheres were not exactly critical, i.e., $k_{\text {eff }}$ deviated slightly from unity.

The critical experimental conditions are given in Table I for all the spheres. In the series with variable temperature, concentrations were calculated from reported masses and volumes since the concentrations are all reported at $25^{\circ} \mathrm{C}$.

\section{III.B Cylinders of Aqueous Solution}

The only experiments at concentrations approaching those at which minimum critical volumes and dimensions occur were performed 
with $\mathrm{UO}_{2}\left(\mathrm{NO}_{3}\right)_{2}$ and $\mathrm{UO}_{2} \mathrm{~F}_{2}$ solutions in paraffin-reflected cylinders.? Most of the cylinders were unreflected on top. An indirect method was used for measuring heights of the uranyl nitrate solutions, resulting in an estimated uncertainty of $3 \%$. The estimated uncertainty for the uranyl fluoride solution heights was $1 \%$. Three or four of the vessels containing $\mathrm{UO}_{2} \mathrm{~F}_{2}$ solutions were coated with Unichrome. (The text says three; four are so indicated in the table of data.) In many cases, there was insufficient material to make the system critical, and critical heights were extrapolated from source multiplication curves. The experimental data for the higher concentration $\mathrm{UO}_{2}\left(\mathrm{NO}_{3}\right)_{2}$ and $\mathrm{UO}_{2} \mathrm{~F}_{2}$ solutions selected for the present work are given in Tables II and III, respectively. Temperature was assumed to be $25^{\circ} \mathrm{C}$; cylinder walls, bottoms, and tops (when present) were 1/16-inch aluminum. The series of experiments with bare and water-reflected spheres of uranyl nitrate solution also included bare and waterreflected cylinders. ${ }^{9}$ According to J. T. Thomas, 10 the data reported for the reflected cylinders are for the case where each cylinder was supported by a $24.3-\mathrm{cm}-\mathrm{h}$ igh cylinder of styrofoam of the same diameter, and some of these data are in error. The mass for the $38.1-\mathrm{cm}$-diameter cylinder at $132 \mathrm{~g} \mathrm{U} / \mathrm{L}$ should be 2.02 instead of $1.77 \mathrm{~kg}$, and the height for the $20.3-\mathrm{cm}$-diameter cylinder at $95.0 \mathrm{~g} \mathrm{U} / \mathrm{L}$ should be 27.02 rather than $20.02 \mathrm{~cm}$. Of more interest are unreported datal0 for the case where the bottom and sides were reflected by water, i.e., the styrofoam was 
replaced by water. These data are given in Table IV. However, even in these experiments, concentrations were not great enough or cylinder diameters small enough to be of much interest in the present work. Critical experiments with bare and water-reflected cylinders have also been done in France. 13 The greatest concentration was $206.5 \mathrm{~g}^{233} \mathrm{U} / \mathrm{L}$, and the smallest cylinder diameter was $25 \mathrm{~cm}$. Hence, again there is little interest in these data in the present work.

Cylinder data in which there is interest are measurements in large cylinders at concentrations close to the minimum critical value for an infinite system. ${ }^{11}$ The reported critical heights contain a correction for bottom structure and are truly bare critical heights. The radius was increased by an assumed wall thickness so that the dimensions in Table $\mathrm{V}$ are estimates of bare critical values. The dimensions are so large that small uncertainties in their exact values have little effect. Temperature was assumed to be $25^{\circ} \mathrm{C}$.

\section{III.C Pertinent Metal Experiments}

Since the critical mass of a water-reflected sphere of ${ }^{233} \mathrm{U}$ has not been measured, it is necessary to infer the appropriate bias for calculations for water-reflected metal and oxide from other experiments. Besides experiments with bare and waterreflected plutonium and ${ }^{235} \mathrm{U}$ spheres, for which correlations have been reported, 1,2 the experiments ${ }^{14}$ isted in Table VI were considered pertinent. Experiments ${ }^{15}$ in which ${ }^{233} \mathrm{U},{ }^{235} \mathrm{U}$, and $\mathrm{Pu}$ 
cores were reflected by Be might also be pertinent, but were not considered.

\section{CORRRLATIONS}

\section{IV.A Aqueous Solutions}

Correlations were made of the three code combinations (HRXNANISN, GLASS-ANISN, and MGBS-TGAN) with the sphere experiments of Table I. The results are recorded in Table VII in the same order as the experiments are 1 isted in Table $\mathrm{I}$. Densities of $\mathrm{UO}_{2} \mathrm{~F}_{2}$ and $\mathrm{UO}_{2}\left(\mathrm{NO}_{3}\right)_{2}$ solutions were calculated as for ${ }^{235} \mathrm{U}$ (Reference 2). $\mathrm{UO}_{2} \mathrm{~F}_{2}$ was represented in $\mathrm{MGBS}$ by $\mathrm{UO}_{4}$. In all codes, aqueous solutions of $\mathrm{VO}_{2}\left(\mathrm{NO}_{3}\right)_{2}$ were treated as solutions of $\mathrm{UO}_{3}$ in nitric acid solutions. For MGBS, densities of $\mathrm{UO}_{3}$ and $\mathrm{UO}_{2} \mathrm{~F}_{2}$ were calculated by $\mathrm{HRXN}$ and were adjusted to densities of natural $\mathrm{UO}_{3}$ and $U q_{4}$. No MGBS-TGAN correlations were made with the two series of sphere experiments in which temperature was a variable. MGBS presumes a temperature of $20^{\circ} \mathrm{C}$. The experiments at lowest temperature were essentially duplicated in the sphere experiments reported along with the paraffin-reflected cylinder experiments. No attempt was made in MGBS to adjust to the temperature of any of the experiments by the introduction of voids. The correlations are expressed in Table VII in terms of the critical values of $k_{e f f}$, i.e., as $1+B i a s$ where Bias $=k_{e f f}(c a l c)-k_{e f f}(\exp t)$. Prior to learning ${ }^{10}$ that the $\mathrm{N} / \mathrm{U}$ ratio was 2.67 in the series of experiments ${ }^{9}$ with $\mathrm{UO}_{2}\left(\mathrm{NO}_{3}\right)_{2}$, the effect of the ratio 
was studied. Increasing the ratio from 2.0 (no free acid) to 2.6 decreased $k_{e f f}$ for both the bare and reflected spheres at about $130 \mathrm{~g} \mathrm{U} / \mathrm{L}$ by about 0.004 . At about $45 \mathrm{~g} / \mathrm{L}$, the reduction was about 0.002 .

Four of the sphere experiments were calculated by McNeany and Jenkins. ${ }^{4}$ Experiments 9, 10, 11, and 12 in their 1 isting correspond, respectively, to experiments $19\left(\mathrm{H} /{ }^{233} \mathrm{U}=192.3\right), 11$ $\left(\mathrm{H} / 23{ }^{23} \mathrm{U}=381.5\right), 23\left(\mathrm{H} /{ }^{233} \mathrm{U}=1532\right)$, and $28\left(\mathrm{H} /{ }^{233} \mathrm{U}=1987\right)$ as listed in Tables $I$ and VII. Their results (by $S_{8}$ quadrature) with Hansen-Roach cross sections ${ }^{16}$ were $0.994,0.988,1.004$, and 1.005 . The first two lie appreciably above the corresponding values of Table VII, and appear to indicate use of the $d E / E$ weighted cross sections for $H$, rather than the fission spectrum weighted values used here. Part of the reason 0.994 lies so far above 0.972 , as calculated here, is their use of $\mathrm{N} / \mathrm{U}=2.0$. (They actually report 0.944 in their Table IX, but 0.994 is shown in their Figure 1.) They also show $F$ as being present, but this may be a typographical error. Their results (also by $S_{8}$ ) with ENDF/B-IV cross sections were, respectively, $1.028,1.013,0.996$, and 0.991 . The first two lie appreciably below the corresponding values of Table VII, presumably reflecting differences in processing codes, resonance absorption calculation, and group structure. The same conclusion is reached, however, namely that Hansen-Roach cross sections underestimate $k_{e f f}$, whereas ENDF/B-IV cross sections overestimate it. 
Correlations with the paraffin-reflected cylinders of $\mathrm{UO}_{2}\left(\mathrm{NO}_{3}\right)_{2}$ solution are given in Table VIII and of $\mathrm{UO}_{2} \mathrm{~F}_{2}$ solution in Table IX in the same order that the experiments are listed in Tables II and III. Since the density of paraffin is somewhat variable (The Chemical Rubber Handbook gives a range of 0.87 to $\left.0.91 \mathrm{~g} / \mathrm{cm}^{3}\right)$, some consideration was given to the effect of variations in density. For a reflected sphere containing solution at about $50 \mathrm{~g}^{233} \mathrm{U} / \mathrm{L}$, increasing the density from 0.87 to 0.91 $\mathrm{g} / \mathrm{cm}^{3}$ increased $k_{\text {eff }}$ (as calculated by HRXN-ANISN) by about 0.005 . At this same concentration, the experimenters found paraffin to be a slightly better reflector than water. ${ }^{7}$ On the basis of their experiments, reflecting a sphere by paraffin rather than by water was calculated (again by HRXN-ANISN) to increase $k_{\text {eff }}$ by about 0.003 .

The approach incorporated in SPBL was used to correlate HRXN-ANISN and GLASS-ANISN with the cylinder experiments. An ANISN calculation was made for each dimension, and $k_{e f f}$ was determined with the transverse dimension assumed infinite (zero transverse buckling). Quadrature was $S_{16}$. Corresponding to each of the values of $k_{e f f}$, SPBL computed the geometric buckling by a $B_{1}$ calculation. The total geometric buckling was obtained by adding the axial and radial components, and the corresponding value of $k_{e f f}$ was calculated, again by $B_{1}$. Values of $k_{\text {eff }}$ so determined are greater than would be obtained by a nonseparable solution such as Monte Carlo or two-dimensional $(R, Z)$ 
transport theory (see Appendix). However, by expressing keff as a function of axial buckling and extrapolating to zero axial buckling, the values appropriate for infinite cylinders can be obtained. For ${ }^{235} \mathrm{U}$ solutions, such values are in agreement with correlations made with spheres. ${ }^{2}$

The variation of $k_{\text {eff }}$ with axial buckling exhibited in Tables VIII and IX is greater than that found for ${ }^{235} \mathrm{U}$ solutions, but does not appear inconsistent with that shown in the study reported in the Appendix. However, the variation with axial buckling as zero is approached is not nearly linear as the study indicates should be the case. Deviations from a straight line fit are outside the limits of error assigned to the data points. For the nitrate solutions, the three highest concentration solutions $(\mathrm{H} / 233 \mathrm{U}=57.9,67.0$, and 84.2$)$ in the $7.55-\mathrm{cm}-\mathrm{radius}$ cylinder have keff's lower than would be expected from the other data. These three values are inconsistent with the assertion that $6.32-$ cm-radius cylinders of these solutions would be subcritical at any height. For ${ }^{235} \mathrm{U}$ solution, a similar disagreement exists with the assertion made by the experimenters that some cylinders would be subcritical at any height. ${ }^{2}$ Similar behavior is shown for the fluoride solutions. In particular, at $\mathrm{H} /{ }^{233} \mathrm{U}=73.9$, the values of $k_{e f f}$ determined for the 8.35 and $7.55-\mathrm{cm}-\mathrm{radius}$ cylinders are inconsistent, as are those for the 6.85 and $6.34-\mathrm{cm}$-radius cylinders. There is less reason to doubt that the smallest $(5.60$ $\mathrm{cm}$ radius) cylinder would be subcritical at any height at all 
concentrations, but at the four highest concentrations the margin appears small. In extrapolating to zero axial buckling, consideration was given to the slope indicated by the study in the Appendix and to the maximum attainable heights in the smallest diameter cylinders. It is expected that the experimenters would have recognized it if these heights corresponded to $k_{e f f}$ close to critical. Estimated critical heights were reported for cases where $k_{\text {eff }}$ calculated for the available height was as much as 0.07 below the value calculated for the estimated height. Correlation of MGBS-TGAN with the cylinder experiments was performed differently. For each dimension, a search was made for the critical transverse buckling. Subtraction of this buckling from the calculated critical buckling yielded the geometric buckling associated with that dimension. The geometric bucklings were combined and $k_{\text {eff }}$ was calculated as

$$
k_{e f f}=\frac{1+M^{2} B_{c}^{2}}{1+M^{2} B_{g}^{2}}
$$

where $\mathrm{B}_{\mathrm{C}}{ }^{2}$ is the calculated critical buckling, $\mathrm{M}^{2}$ is the associated migration area, and $\mathrm{B}_{\mathrm{g}}{ }^{2}$ is the geometric buckling. This approach, according to the Appendix, should give less variation of $k_{\text {eff }}$ with axial buckling. In these correlations, paraffin was considered to be water, since the two appear nearly equivalent and paraffin is not easily introduced as a material in MGBS. Although correlations were made with the experiments of Table IV', they contributed little to the determination of bias and are not reported here. 
Correlations with the large bare cylinders described in Table $V$ are given in Table $X$. The assumptions of separability in SPBL and in the MGBS-TGAN approach introduce minimal error because of the large size. The correlations are given in the same order as the experiments are listed in Table $\mathrm{V}$. The quadrature in the ANISN calculation was $\mathrm{S}_{16}$.

Correlations of HRXN-ANISN, GLASS-ANISN, and MGBS-TGAN with the experiments with spheres and cylinders of aqueous solution are plotted in Figures 1 to 3 . The curves are "eyeball" fits to the data with a tendency to be on the conservative side, especially for GLASS-ANISN and MGBS-TGAN. The steep slope and the coarser (by a factor of 2) vertical scale in Figure 3 should be noted.

\section{IV.B Metal Systems}

Correlations of HRXN-ANISN and GLASS-ANISN with the metal spheres of Table VI are given in Table XI. The calculations were made in exactly the same manner as for ${ }^{235} \mathrm{U}$ and ${ }^{239} \mathrm{Pu}$, reported previously.1,2 The effect of experimental uncertainties was evaluated with Hansen-Roach cross sections by $\mathrm{S}_{4}$ quadrature. In the GLASS calculations for ${ }^{233} \mathrm{U}$, the resonance absorption rate exceeded the source rate from slowing down in a number of groups, as was the case with $235 \mathrm{U}$ and ${ }^{239} \mathrm{Pu}$. (In those groups, the absorption rate was arbitrarily set equal to $99 \%$ of the source rate, as before.) The bare ${ }^{233} \mathrm{U}$ sphere was also calculated by McNeany and Jenkins ${ }^{4}$ with $S_{8}$ quadrature. Their results with Hansen-Roach and with ENDF/B-IV cross sections were, respectively, 
1.008 and 0.967 , in good agreement with Table XI. As they noted, ENDF/B-IV cross sections overestimate $k_{\text {eff }}$ for moderated $233^{3} \mathrm{~J}$ systems and underestimate it for metal.

The bias appropriate for water-reflected metal and oxide cores was selected by combining the results of Table XI with previous results for ${ }^{233} \mathrm{U}$ and ${ }^{239} \mathrm{Pu}$ spheres. ${ }^{1,2}$ with HansenRoach cross sections, the value of $k_{\text {eff }}\left(S_{0}\right)$ for a critical bare plutonium sphere was 1.0018 and for a critical waterreflected sphere was 0.9951 . The corresponding values for a ${ }^{235} \mathrm{U}$ sphere are 1.0004 and 0.9952 . The maximum decrease in $k_{\text {eff }}$ (occurring for plutonium) was applied to the bare sphere result for ${ }^{233} \mathrm{U}$ to obtain a critical value of 0.9970 . With GLASS cross sections, $k_{\text {eff }}$ increased by 0.0098 for water reflection of plutonium, and decreased by 0.0024 for water reflection of ${ }^{235} \mathrm{U}$. The decrease was applied to the bare sphere of ${ }^{233} \mathrm{U}$ to obtain a critical keff of 0.9635 .

\section{SUBCRITICAL LIMITS}

\section{V.A Aqueous Solution}

Al1 three computational methods (HRXN-ANISN, GLASS-ANISN, and MGBS-TGAN) were used to compute limits for solutions. A temperature of $20^{\circ} \mathrm{C}$ was assumed, and all units were surrounded by an effectively infinite thickness of water. The ANISN quadrature was $\mathrm{S}_{16}$. The margin from the curves of Figures 1 to 3 necessary to assure subcriticality is difficult to assess. For the concentration limit, the areal density 1 imit, and the mass limit, a 
margin in $k_{\text {eff }}$ of 0.01 seems sufficient in view of experimental data at the corresponding concentrations. Scatter in the data as plotted in Figures 1 to 3 gives an indication of uncertainty. In similar experiments with spheres of ${ }^{235} U$ solutions, the uncertainty in $k_{\text {eff }}$ associated with quoted uncertainties in dimensions and solution concentrations is well within $\pm 0.005 .^{2}$ A margin of 0.02 should be ample. The dimension 1 imits occur at high concentration where the only data are those obtained with paraffin-reflected cylinders. However, the extrapolations to infinite cylinders are believed to have been done conservatively. Hence, a margin of 0.02 seems sufficient here also. Calculations were carried only as far as the saturated solutions, since limits apply only to homogeneous solutions. Johnson and Kraus, 17 indicate a $66 \%$ solution to be saturated. The equivalent molarity is 5.04 and for the present work a saturated solution was assumed to be 5.0M. Kapustinsky and Lipilina ${ }^{18}$ indicate a $52.36 \%$ (2.3M) solution of uranyl nitrate to be almost saturated and refer to work by others at as high a concentration as $54.77 \%(2.44 \mathrm{M})$. For the present work the saturated solution was assumed to be $2.5 \mathrm{M}$.

Table XII contains "limits", i.e., minimum values calculated to correspond to $k_{\text {eff }} 0.02$ below the curves of Figures 1 to 3 , as calculated by the three computational methods. The quadrature in ANISN was $S_{16}$. Limits now in the Standard, based on Webster's calculations, 19 are shown for comparison, and limits are proposed for the revised Standard. 
Agreement is very good in the case of the concentration limit and would be even better if the curve in Figure 3 were given a sharp upturn at $\mathrm{H} /{ }^{233} \mathrm{U}=1800$, so as to fit the data more closely. The critical concentrations, calculated by the three methods are $11.22,11.20$, and $11.12 \mathrm{~g}^{233} \mathrm{U} / \mathrm{L}$.

MGBS-TGAN does not agree well with the other two methods in the case of areal density. The minimum occurs at a concentration of about $0.1 \mathrm{MM}\left(\mathrm{H} / /^{233} \mathrm{U}=1000\right)$. The $0.334 \mathrm{~g} / \mathrm{cm}^{2}$ limit would increase to about $0.344 \mathrm{~g} / \mathrm{cm}^{2}$ if the curve of Figure 3 were drawn through the neighboring data points at $H /{ }^{233} \mathrm{U}<1000$ rather than below them and if a sharp dip were provided at $\mathrm{H} /{ }^{23}{ }^{3} \mathrm{U}=1800$, as indicated above. This would increase the critical value of $k_{\text {eff }}$ by about 0.01 , and the critical density would increase from 0.355 to $0.365 \mathrm{~g} / \mathrm{cm}^{2}$. The least change in slope as a function of $\mathrm{H} /{ }^{233} \mathrm{U}$ near 1000 is shown by the HRXN-ANISN correlations. Interpolation by way of the curve, to yield critical values of $\mathrm{k}_{\text {eff }}$ near $\mathrm{H} / 235 \mathrm{U}=1000$ should be least open to question in this case. There appears to be no reason to suspect that a margin of 0.02 is insufficient to provide subcriticality or that the Standard 1 imit of $0.35 \mathrm{~g} / \mathrm{cm}^{2}$ might be critical.

The spread in mass values is surprising. The minimum mass occurs at $\mathrm{H} / 233 \mathrm{U} \cong 450$. Redrawing the curve in Figure 3 as indicated above would increase the critical $k_{e f f}$ by about 0.006 and increase the critical mass calculated by MGBS-TGAN by about $16 \mathrm{~g}$ from 550 to $566 \mathrm{~g}$. (As has been noted previously, 1,2 
a margin in $k_{\text {eff }}$ of 0.02 corresponds to a larger increment in mass or other parameter as calculated by MGBS-TGAN than by HRXNANISN or GLASS-ANISN. Here the difference in mass is $53 \mathrm{~g}$ by MGBS-TGAN, $43 \mathrm{~g}$ by HRXN-ANISN.) The fictitious transverse buckling applied in MGBS-TGAN calculations for spheres makes aluminum walls appear to be worth more than they actually are when the critical keff deviates appreciably from unity. Since aluminum walls were present in the experiment, their removal, as in the limit calculations, results in too low a critical mass, in the present case about $8 \mathrm{~g}$ too low. The resulting critical mass, $574 \mathrm{~g}$, is in good agreement with that, $573 \mathrm{~g}$, calculated by HRXNANISN with the critical value of $k_{\text {eff }}$ read from Figure 1. Webster $^{19}$ calculated a critical mass of $570 \mathrm{~g}$. His few correlations with experiment indicate this mass might be subcritical by a margin of about 0.005 in $k_{e f f}$. Previous calculations by $\mathrm{Clark}^{20}$ led to a critical mass of about $600 \mathrm{~g}$, in agreement with that reported by Paxton, et al. 21

The critical mass was not calculated by GLASS-ANISN, but would probably be about $564 \mathrm{~g}$. The curve in Figure 2, however, tends to fall a little below the correlations near $\mathrm{H} /{ }^{233} \mathrm{U}=450$. Although it appears doubtful that $550 \mathrm{~g}$ could be critical, more confidence is provided by reducing the $1 \mathrm{imit}$ and $540 \mathrm{~g}$ is being proposed. It also is proposed that the limit for possibly nonuniform slurries 20 be reduced from 520 to $500 \mathrm{~g}$. 
As indicated in the discussion of calculational methods, MGBS-TGAN should not be considered highly reliable for calculating dimensional limits. Diffusion theory is presumably less accurate than $S_{16}$ transport theory for converting from one shape to another (e.g., from cylinders, for which bias was established, to slabs). The effect of the aluminum walls is overestimated. Limits calculated by this and the other two methods are appreciably below the values in the Standard. The minima as calculated by MGBS-TGAN occur at about 3.5M. With HRXN-ANISN, the volume minimum occurs at $3.5 \mathrm{M}$, the cylinder diameter minimum is at $4.5 \mathrm{M}$, and the slab thickness is still decreasing at 5.OM (saturation). With GLASSANISN, all three are still decreasing at 5.0M.

Limits calculated in the same manner for uranyl nitrate solutions are given in Table XIII, along with values proposed for the standard. The slight differences in concentration and areal density are not worth taking advantage of, and identical limits are proposed for $\mathrm{UO}_{2} \mathrm{~F}_{2}$ and $\mathrm{UO}_{2}\left(\mathrm{NO}_{3}\right)_{2}$. The proposed mass limit for $\mathrm{UO}_{2}\left(\mathrm{NO}_{3}\right)_{2}$ is'simply the value proposed in Table XII plus the increment calculated by HRXN-ANISN and GLASS-ANISN. The dimensional limits as calculated by MGBS-TGAN and by GLASS-ANISN and the slab thickness calculated by HRXN-ANISN are still decreasing at $2.5 \mathrm{M}$ (saturation). However, by HRXN-ANISN, the minimum cylinder diameter occurs at $2.25 \mathrm{M}$, and the minimum volume is at $2.0 \mathrm{M}$. 


\section{V.B Metal and Oxides}

Limits for metal and dry oxide, calculated by HRXN-ANISN and GLASS-ANISN, are given in Table XIV. These limits correspond to $k_{\text {eff }} 0.02$ below the critical value selected by analogy with $235^{U}$ and plutonium experiments. The metal or oxide cores were surrounded by $20 \mathrm{~cm} \mathrm{H} \mathrm{H}_{2} \mathrm{O}$ at $20^{\circ} \mathrm{C}$. The quadrature was $\mathrm{S}_{16}$, the small difference between $S_{16}$ and $s_{\infty}$ being ignored. Since the larger change in the critical $k_{\text {eff }}$ between bare and waterreflected systems was selected, a margin of 0.02 was considered sufficient to assure subcriticality for metal. It was also considered sufficient for oxide since experiments with plutonium oxide indicate no lower critical $k_{\text {eff }}$ for oxide than for metal. ${ }^{1}$ The limits in the standard are based on calculations by Roach and Smith ${ }^{22}$ and are values they calculate from Hansen-Roach cross sections by $S_{8}$ at $k_{\text {eff }}$ (uncorrected for bias) $=0.97$. Not surprisingly, they are consistent with the HRXN-ANISN results by $S_{16}$ at $k_{\text {eff }}=0.977$. The agreement between HRXN-ANISN and GLASS-ANISN is poorer for ${ }^{233} \mathrm{U}$ than for ${ }^{235} \mathrm{U}$ or ${ }^{239} \mathrm{Pu}$ and may indicate selection of too low a critical value of $k_{e f f}$ for water-reflected systems. However, in the absence of a definitive experiment or of a compelling reason for increasing the critical value, the prudent course to follow is to base the limits on the GLASS-ANISN calculations. 
Limits, calculated similarly, for moist oxides at full and half density are given in Table XV. The moisture is limited to $1.5 \%$ as for ${ }^{235} \mathrm{U}$ and ${ }^{239} \mathrm{Pu}$. Volumes of moisture and oxide are assumed to be additive. Comparison of Tables XIV and XV shows that moisture reduces the limiting mass of uranium for all oxides as calculated by either method, but only in the case of the cylinder diameter for $\mathrm{UO}_{3}$ by GLASS-ANISN is a dimension reduced. The moisture content is an upper limit; it would not be practical to require a moisture content of $1.5 \% \mathrm{H}_{2} \mathrm{O}$. The proposed limits in Table XV are then the lower of the dry and moist values. (Although not tabulated here, calculations were also made for dry half-density oxides.)

\section{Acknowledgement}

The information contained in this article was developed during the course of work under Contract DE-AC09-76SR00001 with the U.S. Department of Energy. 


\section{References}

1. H. K. Clark, Nuc l. Sci. Eng. 79, 65 (1981).

2. H. K. Clark, "Subcritical Limits for ${ }^{235} \mathrm{U}$ Systems," submitted for publication in Nucl. Sci. Eng.

3. American National Standard for Nuclear Criticality Safety in Operations with Fissionable Materials Outside Reactors, ANSI N16.1-1975/ANS-8.1, American Nuclear Society.

4. S. R. McNeany and J. D. Jenkins, Nuc1. Sci. Eng., 65, 441 (1978).

5. H. J. Amster, "A Compendium of Thermal Neutron Cross Sections Averaged Over the Spectra of Wigner and Wilkins," WAPD-185 (1958).

6. J. T. Thomas, J. K. Fox, and Dixon Callihan, Nucl. Sci. Eng., $1,20(1956)$ :

7. J. K. Fox, L. W. Gilley, and E. R. Rohrer "Critical Mass Studies, Part VIII Aqueous Solutions of 233 U," ORNL-2143 (1959).

8. J. K. Fox, J. T. Thomas, and E. R. Rohrer, "Critical Mass Studies of Aqueous Solutions of $233 \mathrm{U}, "$ ORNL-1715, pp. 11-12 (1954).

9. J. T. Thomas, "Critical Experiments with Aqueous Solutions of ${ }^{\mathrm{UO}_{2}}\left(\mathrm{NO}_{3}\right)_{2}$," Neutron Physics Division Annual Progress Report 1968, pp. 53-55, ORNL-4280 (1968).

10. J. T. Thomas, Private Communication (1980).

11. R. Gwin and D. W. Magnuson, Nucl. Sci. Eng. 12, 364 (1962).

12. Alan Staub, D. R. Harris, and Mark Goldsmith, Nucl. Sci. Eng., 34, 263 (1968).

13. Jean-Georges Bruna, et al., "Alecto-Resultats des Experiences Critiques Homogenes Realisees sur le ${ }^{239} \mathrm{Pu},{ }^{235} \mathrm{U}$ et ${ }^{23}{ }^{3}$," CEA-R 2814 (1965).

14. G. E. Hansen and H. C. Paxton, "Reevaluated Critical Specifications of Some Los Alamos Fast-Neutron Systems," LA-4208 (1969). 
15. H. C. Paxton, "Los Alamos Critical-Mass Data," LA-3067-MS (Rev. 1975).

16. G. E. Hansen and W. H. Roach, "Six and Sixteen Group Cros s Sections for Fast and Intermediate Assemblies," LAMS-2543 (1961).

17. J. S. Johnson and K. A. Kraus, J. Am. Chem. Soc. 75, 4594 (1953).

18. A. F. Kapustinsky and I. I. Lipilina, "The Densities of Aqueous Uranyl Nitrate Solutions and the Apparent Molar Volumes of Uranyl Nitrate," Bul1. Acad. Sci. USSR, Div. Chemical-Science, 661 (1956).

19. J. W. Webster, "Calculated Neutron Multiplication Factors of Uniform Aqueous Solutions of ${ }^{23} \mathrm{U}$ and $23{ }^{2} \mathrm{U}, "$ ORNL-CDC-2 (1967).

20. H. K. Clark, Nuc1. Sci. Eng. 24, 133 (1966).

21. H. C. Paxton, J. T. Thomas, Dixon Callihan, and E. B. Johnson, "Critical Dimensions of Systems Containing $\mathrm{U}^{235}, \mathrm{Pu}^{239}$, and $\mathrm{U}^{233}, " \mathrm{TID}-7028$ (1964).

22. W. H. Roach and D. R. Smith, "Estimate of Maximum Subcritical Dimensions of Single Fissile Metal Units," ORNL-CDC-3 (1967). 


\section{Appendix}

To gain a better understanding of the application of onedimensional methods to two-dimensional problems, i.e., finite cylinders, some critical, mathematical benchmark cases were calculated by TWOTRAN ${ }^{1}$ and were analyzed in various ways by onedimensional methods. The cases selected were cylinders of ${ }^{233} \mathrm{UO}_{2} \mathrm{~F}_{2}$ solution containing $400 \mathrm{~g}^{233} \mathrm{U} / \mathrm{L}$, with various height (H) to diameter (D) ratios, and reflected by $15 \mathrm{~cm}$ of water. In some cases, an aluminum wall was interposed. To limit computer time, the calculations were made with two energy groups, isotropic scattering, and no upscatter. The macroscopic cross sections were generated by GLASS from ENDF/B-IV cross sections and are given in Table A.1. Calculations were made with a uniform mesh in each material, using 0.2 times the number of radial intervals and 0.8 times the number of axial intervals prescribed in empirical formulas. ${ }^{2}$ Typically, the number of mesh volumes was of the order of 600 . Quadrature was $S_{16}$ to give an accurate solution. ANISN was used to calculate the infinite slab. Calculations have shown a disagreement between TWOTRAN and ANISN for the infinite cylinder corresponding to about $1 \%$ in $k_{\text {eff }}$ with only $s_{4}$ quadrature;

agreement is much better with $\mathrm{s}_{16}$. The CPU time was about 20 minutes on an IBM Model 195 for each cylinder. Results are given in Table A.2. The code indicated that the problems were converged in all cases despite the specified inner iteration limit of 10 always being reached in the thermal group. 
The first method applied to these benchmarks was ANISN-SPBL with the $P_{0}$ cross sections of Table A.l and with $S_{16}$ quadrature. In this approach, $k_{\text {eff }}$ is calculated for each dimension of a finite cylinder with the other dimension assumed to be infinite. Geometric bucklings are calculated (by $B_{1}$ ) corresponding to each value of $k_{e f f}$ and are added to obtain the total geometric buckling. The value of $k_{\text {eff }}$ corresponding to this buckling is then calculated (again by $B_{1}$ ). Table A.3 gives results obtained by this method for the benchmark cases of Table A.2. The method overestimates $k_{\text {eff }}$ for finite cylinders, but the overestimate decreases as the infinite cylinder is approached (i.e., as axial buckling approaches zero) and $k_{\text {eff }}$ becomes very nearly a linear function of axial buckling. (The failure of $k_{\text {eff }}$ to be exactly unity for the infinite cylinder in Table A.3 represents the slight discrepancy between ANISN and TWOTRAN with $\mathrm{S}_{16}$ quadrature.) Thus, linear extrapolation of $\mathrm{k}_{\text {eff }}$ as a function of axial buckling should be a valid procedure for obtaining the critical value of $k_{e f f}$ for an infinite cylinder and hence the bias of the calculational method. An additional test of this thesis was made by repeating the ANISN-SPBL analysis of the benchmarks, but with Hansen-Roach cross sections ( 16 groups, $P_{1}$ scattering). The aluminum-walled cylinders and the cylinders with $H / D=0$ and 0.25 were omitted. Results are given in Table A.4, and again $k_{\text {eff }}$ is nearly linear with $\mathrm{B}_{\mathrm{H}}{ }^{2}$ at small $\mathrm{B}_{\mathrm{H}}{ }^{2}$, albeit with slightly larger slope. The low values of 
$k_{\text {eff }}$ are consistent with the finding that, at high concentrations of $233 \mathrm{U}, \mathrm{ENDF} / \mathrm{B}-\mathrm{IV}$ cross sections underestimate the critical mass, whereas Hansen-Roach cross sections overestimate it.

Another method of analyzing two-dimensional critical bodies by one-dimensional codes, the one incorporated in TGAN, is to search for the critical transverse buckling corresponding to each critical dimension. The geometric buckling of a finite cylinder is then $\mathrm{B}_{\mathrm{g}}{ }^{2}=2 \mathrm{~B}_{\mathrm{C}}{ }^{2}-\mathrm{B}_{\mathrm{r}}{ }^{2}-\mathrm{B}_{\mathrm{h}}{ }^{2} \cdot \mathrm{B}_{\mathrm{c}}{ }^{2}$ is the critical buckling calculated from composition and cross sections. $\mathrm{B}_{\mathrm{r}}{ }^{2}$ and $\mathrm{B}_{\mathrm{h}}{ }^{2}$ are, respectively, the transverse (radial) buckling calculated to make a slab with thickness equal to the cylinder height critical and the transverse (axial) buckling calculated to make the cylinder critical. The value of $k_{e f f}$ calculated for the critical finite cylinder is the value calculated to correspond to this geometric buckling. This method, implemented by ANISN with the cross sections of Table A.l, was applied to the benchmarks.* The transverse leakage is calculated as $D B_{t r}{ }^{2}$ and is treated as an equivalent absorption. With $D=1 / 3 \Sigma_{\mathrm{tr}}$ poor results were obtained $\left(k_{\text {eff }} \cong 0.95\right)$. Much better results were obtained with

$$
D=\left(\frac{\Sigma}{B^{2}} \frac{B / \Sigma}{\tan ^{1}(B / \Sigma)}\right)-1
$$

* In similar calculations, ${ }^{3}$ discrepancies have been found in that $k_{\text {eff }}$ calculated by ANISN at the critical transverse buckling determined by ANISN deviated somewhat from unity, but such discrepancies were not found in the present case. 
the correct transport theory expression for isotropic scattering. Results of the calculations are given in Table A.5. With only water reflection, the method gives very good results for the finite cylinders, but with the aluminum wall interposed, $k_{\text {eff }}$ is too low due to streaming in the aluminum resulting from the assumption of separability.

The same method as implemented by TGAN with diffusion theory constants was applied to the benchmarks. In one case, the constants were derived by GLASS; in the other, by MGBS. Results are given in Table A.6. Diffusion theory agrees fairly well with transport theory. The large values of $k_{\text {eff }}$ calculated with MGBS cross sections are consistent with the biases found in correlations with experiment. Again, the effect calculated for the aluminum wall is too large. 


\section{References}

1. K. D. Lathrop and F. W. Brinkley, "TWOTRAN-II: An Interfaced, Exportable Version of the TWOTRAN Code for Two-Dimensional Transport," LA-4848-MS (1973).

2. R. G. Soltesz, et al., "Nuclear Rocket Shielding Methods Modification, Updating, and Input Data Preparation, Vol IV, One Dimensional Discrete Ordinates Transport Technique. Fina1 Progress Report," WANL-PR(LL)-034 (1970).

3. H. K. Clark, "Snake Bites from Code Misuse and Overuse," Proceedings Nuclear Criticality Safety, SAND-80-1675 (1980). 
Table I

Critical Spheres of ${ }^{233} \mathrm{u}$ Solution

\begin{tabular}{|c|c|c|c|c|c|c|c|c|c|}
\hline $\begin{array}{l}\text { Isotopic } \\
\text { Comp. }\end{array}$ & $\mathrm{g} \mathrm{U} / \mathrm{L}$ & $\mathrm{g} \mathrm{NO}_{3}^{-} / \mathrm{L}^{\mathrm{b}}$ & gTh/L ${ }^{c}$ & $g B / L^{d}$ & $\begin{array}{c}\text { Radius, } \\
\mathrm{cm}\end{array}$ & $\begin{array}{c}\text { Wall Thickness, } \\
\mathrm{cm}\end{array}$ & $\operatorname{Refl}^{f}$ & Temp, ${ }^{\circ} \mathrm{C}$ & Ref \\
\hline \multirow[t]{5}{*}{1} & 61.95 & 0 & 0 & 0 & 13.21 & 0.13 & $\mathrm{H}_{2} \mathrm{O}$ & 32.0 & 6 \\
\hline & 62.44 & & & & 13.22 & & & 39.5 & \\
\hline & 63.79 & & & & 13.23 & & & 65.5 & \\
\hline & 64.92 & & & & 13.24 & & & 83.2 & \\
\hline & 66.39 & & & & 13.25 & & & 96.5 & \\
\hline \multirow[t]{3}{*}{1} & 39.23 & 0 & 0 & 0 & 15.96 & $0.13^{g}$ & $\mathrm{H}_{2} \mathrm{O}$ & 26.3 & 6 \\
\hline & 40.01 & & & & 15.96 & & & 56.0 & \\
\hline & 41.72 & & & & 15.97 & & & 99.5 & \\
\hline 1 & 68.22 & 0 & 0 & 0 & 15.96 & $0.13^{g}$ & None & 27.0 & 6 \\
\hline 2 & 62.8 & 43.9 & 0 & 0 & 13.21 & 0.13 & $\mathrm{H}_{2} \mathrm{O}$ & $25^{h}$ & 7 \\
\hline 1 & 67.9 & 0 & 0 & 0 & $15.95^{i}$ & $0.13^{\mathrm{g}}$ & None & $25^{h}$ & 7 \\
\hline \multirow[t]{3}{*}{1} & 66.9 & 0 & 0 & 0 & $13.04^{j}$ & 0.13 & $\mathrm{H}_{2} \mathrm{O}$ & $25^{h}$ & 7 \\
\hline & 61.8 & & & & $13.20^{\mathrm{i}}$ & & & & \\
\hline & 60.8 & & & & $13.28^{\mathrm{k}}$ & & & & \\
\hline 1 & 39.5 & 0 & 0 & 0 & 15.96 & $0.13^{g}$ & $\mathrm{H}_{2} \mathrm{O}$ & $25^{h}$ & 7 \\
\hline \multirow[t]{3}{*}{3} & 132 & 93.7 & 0 & 0 & 11.170 & 0.122 & $\mathrm{H}_{2} \mathrm{O}$ & $25^{h}$ & 9,10 \\
\hline & 95 & 67.5 & 0 & 0 & 11.847 & & & & \\
\hline & 47.9 & 34.0 & 0 & 0 & 14.579 & & & & \\
\hline 3 & 131 & 93.0 & 0 & 0 & 14.579 & 0.122 & None & $25^{h}$ & 9,10 \\
\hline
\end{tabular}


Table I (cont.)

\begin{tabular}{|c|c|c|c|c|c|c|c|c|c|}
\hline $\begin{array}{l}\text { I sotopic } \\
\text { Comp. }^{\mathbf{a}} \\
\end{array}$ & $\mathrm{g} \mathrm{U} / \mathrm{L}$ & $\mathrm{g} \mathrm{NO}_{3}^{-} / \mathrm{L}^{\mathrm{b}}$ & $\underline{g}$ Th/L ${ }^{c}$ & $\mathrm{gB} B / \mathrm{L}^{\mathrm{d}}$ & $\begin{array}{l}\text { Radius, } \\
\mathrm{cm}\end{array}$ & $\begin{array}{l}\text { Wal1 Thickness, } \\
\mathrm{cm} \text { e } \\
\end{array}$ & $\operatorname{Refl}^{f}$ & Temp, ${ }^{\circ} \mathrm{C}$ & Ref \\
\hline \multirow{8}{*}{4} & 102 & 72.4 & 0 & 0 & 15.078 & & & & \\
\hline & 74.6 & 53.0 & 0 & 0 & 15.821 & & & & \\
\hline & 44.6 & 31.7 & 0 & 0 & 18.378 & & & & \\
\hline & 17.14 & 12.17 & 0.076 & 0 & $34.6^{1}$ & 0.32 & None & 20.0 & 11 \\
\hline & 17.86 & 12.61 & 0.079 & 0.0239 & & & & & \\
\hline & 18.52 & 13.15 & 0.082 & 0.0465 & & & & & \\
\hline & 19.18 & 13.56 & 0.085 & 0.0688 & & & & & \\
\hline & 19.82 & 13.99 & 0.087 & 0.0912 & & & & & \\
\hline 5 & 13.25 & 7.72 & 0.057 & 0 & $61.0^{\mathrm{m}}$ & 0.77 & None & 20.0 & 11 \\
\hline
\end{tabular}

a) Isotopic Composition in weight :

\begin{tabular}{|c|c|c|c|c|}
\hline & ${ }^{233} \mathrm{U}$ & ${ }^{234} \mathrm{U}$ & ${ }^{235} \mathrm{U}$ & ${ }^{238} \mathrm{U}$ \\
\hline 1 & 98.7 & 0.54 & 0.04 & 0.72 \\
\hline 2 & 98.7 & 0.5 & 0.01 & 0.79 \\
\hline 3 & 97.53 & 1.05 & 0.03 & 1.39 \\
\hline 4 & 97.70 & 1.62 & 0.04 & 0.64 \\
\hline 5 & 97.67 & 1.54 & 0.03 & 0.76 \\
\hline
\end{tabular}

b) If $\mathrm{NO}_{3}^{-}$concentration is zero, solute was $\mathrm{UO}_{2} \mathrm{~F}_{2}$ 
c) Assumed present as $\mathrm{ThO}_{2}$ at $9.86 \mathrm{~g} / \mathrm{cm}^{3}$

d) Assumed present as $\mathrm{B}_{2} \mathrm{O}_{3}$ at $2.17 \mathrm{~g} / \mathrm{cm}^{3}$

e) All vessel walls were aluminum

f) Water reflector effectively infinitely thick $\geqslant 20 \mathrm{~cm}$ )

g) Vessel was coated internal1y with Unichrome, mocked up by $0.016 \mathrm{~cm}$ of $\mathrm{CH}_{2} \mathrm{CH} \mathrm{Cl}$ with density $1.4 \mathrm{~g} / \mathrm{cm}^{3}$ or equivalently in GLASS by $0.0092 \%{ }^{10} \mathrm{~B}$ by weight in the vesse 1 wall and in MGBS by $0.034 \mathrm{~cm}$ Fe. (Amount required to increase critical $235 \mathrm{U}$ concentration by $2 \%$ ).

h) Assumed temperature

i) Sphere volume reduced $40 \mathrm{~cm}^{3}$ to compensate for void above solution

j) Sphere volume reduced $380 \mathrm{~cm}^{3}$ to compensate for void above solution

k) Sphere volume extrapolated from source multiplication curves

1) Corrected values of $k_{\text {eff }}$ in order of increasing B concentration: 1.0002, 1.0008, 1.0009, 1.0000, 1.0001

m) Corrected value of $k_{\text {eff }} 1.0001$ 
Table II

Critical Paraffin - Reflected Cylinders ${ }^{a}$ of Uranyl Nitrate Solution

\begin{tabular}{|c|c|c|c|c|}
\hline $\mathrm{gU} / \mathrm{L}^{\mathrm{b}}$ & $\mathrm{gNO}_{3}^{-} / \mathrm{L}$ & Radius, cm & $\begin{array}{r}\text { Critical } \\
\text { Height, } \mathrm{cm} \\
\end{array}$ & Maximum Expt. Ht., cm \\
\hline 496.5 & 346.8 & 10.25 & $16.1 \pm 0.2$ & 14.0 \\
\hline \multirow[t]{4}{*}{386.0} & 269.7 & 6.32 & c & 51 \\
\hline & & 7.55 & 27.9 & \\
\hline & & 9.53 & 16.3 & \\
\hline & & 10.25 & 14.4 & \\
\hline \multirow[t]{3}{*}{340.4} & 237.8 & 6.32 & c & 59 \\
\hline & & 7.55 & 29.0 & $\therefore \quad \therefore$ \\
\hline & & 9.53 & 16.2 & \\
\hline \multirow[t]{3}{*}{278.6} & 194.6 & 6.32 & c & 61 \\
\hline & & 7.55 & 30.7 & \\
\hline & & 10.25 & 14.7 & \\
\hline \multirow[t]{2}{*}{200.6} & 140.1 & 7.55 & $38.5 \pm 0.5$ & 36.8 \\
\hline & & 10.25 & 16.4 & \\
\hline \multirow[t]{3}{*}{169.2} & 118.2 & 6.32 & c & 55 \\
\hline & & 9.53 & 18.6 & \\
\hline & & 10.25 & 16.7 & \\
\hline \multirow[t]{2}{*}{162.1} & 113.2 & 7.55 & $46.8 \pm 0.5$ & 45.4 \\
\hline & & 10.25 & 16.7 & \\
\hline \multirow[t]{2}{*}{128.7} & 89.9 & 7.55 & $73 \pm 2$ & 55.4 \\
\hline & & 10.25 & 18.8 & \\
\hline
\end{tabular}

a) Paraffin was assumed to be $\mathrm{CH}_{2}$ with density $0.89 \mathrm{~g} / \mathrm{cm}^{3}$. Where cylinder radii differ from reported values, they were derived from reported volumes and heights. Only the 9.53 and $10.25 \mathrm{~cm}$ radius cylinders had top reflectors. Walls, bottom, and top (where present) were assumed to be $0.16 \mathrm{~cm}$ aluminum; temperature, $25^{\circ} \mathrm{C}$.

b) Uranium contained $98.7 \% 233 \mathrm{U}, 0.5 \% 234 \mathrm{U}, 0.01 \% 235_{\mathrm{U}}, 0.79 \% 238 \mathrm{U}$ by weight.

c) Apparently subcritical at any height. 
Table III

Critical Paraffin - Reflected Cylinders ${ }^{a}$ of Uranyl Fluoride Solution

$\underline{\mathrm{g} U / \mathrm{L}^{\mathrm{b}}}$

693.0

693.0

608.9

526.8

456.9

336.4

Radius, cm

5.60

6.34

8.35

5.60

6.34

8.35

5.60

6.34

8.35

5.60

8.35

5.60

6.34

6.85

7.55

8.35
Critical Height, $\mathrm{cm}$

c

$38 \pm 2$

$20 \pm 1$

c

$41 \pm 2$

$16.7 \pm 0.2$

c

$41 \pm 1$

16.9

c

$18.0 \pm 0.3$

c

$56.5 \pm 0.5$

$48.7 \pm 0.5$

24.0

$19.1 \pm 0.4$
Maximum Expt. Ht., cm

29.9

23.8

13.5

34.9

27.6

16.3

42.6

32.4

49.0

16.9

68.5

53.3

46.3

16.9

a) Paraffin was assumed to be $\mathrm{CH}_{2}$ with density $0.89 \mathrm{~g} / \mathrm{cm}^{3}$. Only the $8.35 \mathrm{~cm}$ radius cylinder had a top reflector. Walls, bottom, and top (where present) were assumed to be $0.16 \mathrm{~cm}$ aluminum; temperature, $25^{\circ} \mathrm{C}$. All except the $6.34 \mathrm{~cm}$ radius (and perhaps the $7.55 \mathrm{~cm}$ radius) cylinder were coated with Unichrome, mocked up by $0.016 \mathrm{~cm}$ of $\mathrm{CH}_{2} \mathrm{CH} \mathrm{Cl}$ with density $1.4 \mathrm{~g} / \mathrm{cm}^{3}$ or equivalently in GLASS by $0.0074 \%$ $10_{B}$ in the vessel wall and in MGBS by $0.034 \mathrm{~cm} \mathrm{Fe}$.

b) Uranium contained $98.7 \%^{233} \mathrm{U}, 0.54 \% 234 \mathrm{U}, 0.04 \% 235 \mathrm{U}, 0.72 \% 238 \mathrm{U}$ by weight.

c) Apparently subcritical at any height. 


$$
\begin{gathered}
\text { Table IV } \\
\text { Water-reflected Cylinders }{ }^{a} \text { of }{ }^{233} \mathrm{UO}_{2}\left(\mathrm{NO}_{3}\right) \text { Solution }
\end{gathered}
$$

Conc.

132

95.0

47.9

\begin{tabular}{|c|c|c|}
\hline 38.1 & 25.3 & 20.3 \\
\hline 11.80 & 15.49 & 21.16 \\
\hline c & 17.92 & 25.40 \\
\hline 18.06 & 25.90 & c \\
\hline
\end{tabular}

Critical height $(\mathrm{cm})$ for Diameter $(\mathrm{cm})$ of:

a) Aluminum cylinders with $0.15 \mathrm{~cm}$ wall, $1.27 \mathrm{~cm}$ thick bottom, no top reflector.

b) Uranium contained $97.53 \%{ }^{233} \mathrm{U}, 1.05 \%{ }^{234} \mathrm{U}, 0.03 \% 235 \mathrm{U}, 1.39 \%{ }^{238} \mathrm{U}$ by weight.

c) Insufficient material for criticality. 


\section{Table V}

\section{Bare Critical Cylinders of Low Concentration Solution}

\begin{tabular}{|c|c|c|c|c|c|c|c|c|}
\hline \multirow[b]{2}{*}{ Radius, $\mathrm{cm}$} & \multirow[b]{2}{*}{$\mathrm{gU} / \mathrm{L}$} & \multicolumn{4}{|c|}{ wt $\%$} & \multirow[b]{2}{*}{$\mathrm{gTh} / \mathrm{L}^{\mathrm{a}}$} & \multirow[b]{2}{*}{$\mathrm{gNO}=\frac{1}{3}$} & \multirow[b]{2}{*}{$\mathrm{Ht}, \mathrm{cm}$} \\
\hline & & ${ }^{23} 3_{U}$ & ${ }^{234} \mathrm{U}$ & ${ }^{235} \mathrm{U}$ & ${ }^{238} \mathrm{U}$ & & & \\
\hline \multirow[t]{4}{*}{155.5} & 14.50 & 97.37 & 1.50 & 0.04 & 1.09 & 0.014 & 8.47 & 50.85 \\
\hline & 13.89 & 97.35 & 1.52 & 0.05 & 1.08 & 0.012 & 8.77 & 60.58 \\
\hline & 13.22 & 97.30 & 1.49 & 0.05 & 1.16 & 0.014 & 8.24 & 79.04 \\
\hline & 12.53 & 97.24 & 1.55 & 0.05 & 1.16 & 0.100 & 8.23 & 140.16 \\
\hline
\end{tabular}

a) Assumed present as $\mathrm{ThO}_{2}$ at $9.86 \mathrm{~g} / \mathrm{cm}^{3}$ 
Table VI

Critical Metal Spheres

Region Isotopic Composition

Core

Core

$\operatorname{Core}^{\mathrm{a}}$

Ref1.

Core

Ref1.

Core

Ref1.
Density, $\mathrm{g} / \mathrm{cm}^{3}$

18.424

18.75

15.778

18.80

18.621

18.8

18.644

18.8
Core radius or Reflector Thickness, cm

$5.983 \pm 0.008$

5.042

$1.664 \pm 0.016$

5.044

$1.222 \pm 0.012$

4.600

$1.989 \pm 0.020$

a) Contained $1.0 \% \mathrm{Ga}$ by wt. 
Correlation of HRXN-ANISN, GLASS-ANISN, and MGBS-TGAN with Critical Spheres of Table I

\begin{tabular}{|c|c|c|c|c|}
\hline $\mathrm{g} \mathrm{U} / \mathrm{L}$ & $\mathrm{H} /^{233} \mathrm{U}^{\mathrm{a}}$ & HRXN-ANISN $\left(S_{\infty}\right)$ & $\begin{array}{l}k_{\text {eff }} \\
\text { GLASS-ANISN }\left(S_{\infty}\right)\end{array}$ & MGBS-TGAN \\
\hline 61.95 & 417.5 & 0.9890 & 1.0376 & - \\
\hline 62.44 & 413.2 & 0.9898 & 1.0388 & - \\
\hline 63.79 & 399.1 & 0.9886 & 1.0386 & - \\
\hline 64.92 & 387.5 & 0.9868 & 1.0377 & - \\
\hline 66.39 & 375.1 & 0.9870 & - & - \\
\hline 39.23 & 662.5 & 0.9971 & 1.0310 & - \\
\hline 40.01 & 641.7 & 0.9988 & 1.0320 & - \\
\hline 41.72 & 598.0 & 1.0007 & - & - \\
\hline 68.22 & 379.4 & 0.9821 & 1.0359 & - \\
\hline 62.8 & 406.9 & 0.9839 & 1.0324 & $1: 0542$ \\
\hline 67.9 & 381.5 & 0.9770 & 1.0346 & 1.0736 \\
\hline 66.9 & 387.2 & 1.0043 & 1.0480 & 1.0679 \\
\hline 61.8 & 419.4 & 0.9886 & 1.0370 & 1.0577 \\
\hline 60.8 & 426.4 & 0.9894 & 1.0374 & 1.0576 \\
\hline 39.5 & 658.2 & 0.9990 & 1.0333 & 1.0458 \\
\hline 132 & 190.7 & 0.9742 & 1.0395 & 1.0789 \\
\hline 95 & 268.8 & 0.9751 & 1.0333 & 1.0650 \\
\hline 47.9 & 542.6 & 0.9859 & 1.0261 & 1.0430 \\
\hline 131 & 192.3 & 0.9704 & 1.0449 & 1.1100 \\
\hline 102 & 249.7 & 0.9745 & 1.0426 & 1.0960 \\
\hline 74.6 & 345.0 & 0.9713 & 1.0313 & 1.0726 \\
\hline 44.6 & 583.5 & 0.9872 & 1.0323 & 1.0526 \\
\hline 17.14 & 1532 & 1.0007 & 1.0049 & 1.0076 \\
\hline 17.86 & 1470 & 1.0001 & 1.0043 & 1.0075 \\
\hline 18.52 & 1418 & 0.9995 & 1.0036 & 1.0073 \\
\hline 19.18 & 1368 & 1.0002 & 1.0044 & 1.0084 \\
\hline 19.82 & 1324 & 0.9994 & 1.0036 & 1.0080 \\
\hline 13.25 & 1987 & 1.0039 & 0.9964 & 1.0078 \\
\hline
\end{tabular}

a) Actually H/Fissile. Includes trace of ${ }^{235} \mathrm{U}$ where present. The ratio was calculated from concentrations and density formulas. 
Table VIII

Values of $k_{\text {eff }}$ Calculated for Critical Cylinders of Table II

\begin{tabular}{|c|c|c|c|c|c|c|c|}
\hline \multirow{2}{*}{\multicolumn{2}{|c|}{$\mathrm{H} /{ }^{233} \mathrm{U}^{\mathrm{a}}$}} & \multicolumn{3}{|c|}{$\mathrm{B}_{\mathrm{H}}^{2}, \mathrm{~cm}^{-2}$} & \multicolumn{3}{|c|}{$k_{\text {eff }}^{b}$} \\
\hline & & HRXN & GLASS & MGBS & HRXN & GLASS & MGBS \\
\hline \multirow{2}{*}{\multicolumn{2}{|c|}{42.6}} & 0 & 0 & 0 & $0.98(?)$ & $1.05(?)$ & - \\
\hline & & 0.01067 & 0.01114 & 0.01324 & $1.0616 \pm 0.0091$ & 1.1518 & 1.1679 \\
\hline \multirow[t]{6}{*}{57.9} & & 0 & 0 & 0 & 0.96 & 1.03 & 1.11 \\
\hline & c & 0 & 0 & 0 & 0.9801 & 1.0563 & 1.1259 \\
\hline & & $<0.00262$ & - & $<0.00281$ & $>0.9408$ & $>1.0170$ & $>1.0881$ \\
\hline & & 0.00685 & 0.00695 & 0.00748 & $0.9793 \pm 0.0045$ & 1.0617 & 1.1055 \\
\hline & & 0.01075 & 0.01114 & 0.01324 & $1.0358 \pm 0.0063$ & 1.1197 & 1.1254 \\
\hline & & 0.01235 & 0.01284 & 0.01522 & $1.0422 \pm 0.0063$ & 1.1262 & 1.1268 \\
\hline \multirow[t]{5}{*}{67.0} & & 0 & 0 & 0 & 0.96 & 1.03 & 1.11 \\
\hline & c & 0 & 0 & 0 & 0.9778 & 1.0517 & 1.1166 \\
\hline & & $<0.00205$ & - & $<0.00219$ & $>0.9496$ & $>1.0208$ & $>1.0871$ \\
\hline & & 0.00649 & 0.00657 & 0.00709 & $0.9845 \pm 0.0047$ & 1.0645 & 1.1018 \\
\hline & & 0.01093 & 0.01130 & 0.01341 & $1.0340 \pm 0.0064$ & 1.1154 & 1.1142 \\
\hline \multirow{5}{*}{\multicolumn{2}{|c|}{84.2}} & 0 & 0 & 0 & 0.965 & 1.03 & 1.10 \\
\hline & & 0 & 0 & 0 & 0.9705 & 1.0408 & 1.1002 \\
\hline & & $<0.00195$ & - & $<0.00207$ & $>0.9415$ & $>1.0118$ & $>1.0724$ \\
\hline & & 0.00598 & 0.00605 & 0.00652 & $0.9877 \pm 0.0042$ & 1.0639 & 1.0929 \\
\hline & & 0.01239 & 0.01279 & 0.01506 & $1.0418 \pm 0.0063$ & 1.1194 & 1.1038 \\
\hline \multirow{3}{*}{\multicolumn{2}{|c|}{121}} & 0 & 0 & 0 & 0.97 & 1.04 & 1.095 \\
\hline & & 0.00422 & 0.00424 & 0.00457 & $0.9973 \pm 0.0047$ & 1.0668 & 1.0884 \\
\hline & & 0.01117 & 0.01146 & 0.01342 & $1.0489 \pm 0.0068$ & 1.1207 & 1.0952 \\
\hline
\end{tabular}


Table VIII (cont)

Values of $k_{\text {eff }}$ Calculated for Critical Cylinders of Table II

\begin{tabular}{|c|c|c|c|c|c|c|}
\hline \multirow{2}{*}{${ }^{233} \mathrm{u}^{\mathrm{a}}$} & \multicolumn{3}{|c|}{$\mathrm{B}_{\mathrm{H}}^{2}, \mathrm{~cm}^{-2}$} & \multicolumn{3}{|c|}{$k_{e f f}^{b}$} \\
\hline & HRXN & GLASS & MGBS & HRXN & GLASS & MGBS \\
\hline 45 & 0 & 0 & 0 & 0.98 & 1.045 & 1.085 \\
\hline c & 0 & 0 & 0 & 0.9323 & 0.9942 & 1.0512 \\
\hline & $<0.00234$ & - & $<0.00250$ & $>0.8988$ & $>0.9607$ & $>1.0185$ \\
\hline & 0.00970 & 0.00910 & 0.01158 & $1.0250 \quad 0.0065$ & 1.0934 & 1.0726 \\
\hline & 0.01105 & 0.01132 & 0.01318 & 1.03850 .0067 & 1.1071 & 1.0796 \\
\hline 52 & 0 & 0 & 0 & 0.98 & 1.045 & 1.085 \\
\hline & 0.00308 & 0.00309 & 0.00330 & 0.99690 .0033 & 1.0619 & 1.0829 \\
\hline & - & - & 0.01319 & - & - & 1.0744 \\
\hline 94 & 0 & 0 & 0 & 0.99 & 1.05 & 1.08 \\
\hline & 0.00145 & 0.00145 & 0.00151 & $0.9968 \quad 0.0022$ & 1.0563 & 1.0801 \\
\hline & 0.00973 & 0.00992 & 0.01148 & $1.0340 \quad 0.0067$ & 1.0972 & 1.0696 \\
\hline
\end{tabular}

a.) Ratio calculated from reported concentrations and from density formula. May differ slightly from reported ratio.

b.) First line for each mixture is extrapolated critical value of $k_{e f f}$ for an infinite cylinder of the mixture. Uncertainty in $\mathrm{k}_{\mathrm{eff}}$ corresponds to reported uncertainty of $3 \%$ in measured height and uncertainty associated with extrapolation to criticality from source multiplication curves, and was calculated by HRXN-ANISN-SPBL only. Order of listing is the same as in Table II.

c.) First line enclosed by brace gives $k_{\text {eff }}$ if cylinder which "apparently cannot be made critical at any height" were exactly critical at infinite height. Second line gives axial buckling and $k_{\text {eff }}$ corresponding to maximum height achieved with avallable solution. GLASS-ANISN-SPBL values were inferred from HRXN-ANISN-SPBL. 
Table IX

Values of $k_{e f f}$ Calculated for Critical Cylinders of Table III

$\mathrm{B}_{\mathrm{H}}{ }^{2} \mathrm{~cm}^{-2}$

$\underline{\mathrm{H} / 233 \mathrm{U}^{\mathrm{a}}}$

HRXN

\begin{tabular}{ccc} 
GLASS & & MGBS \\
\cline { 1 - 1 } 0 & & 0 \\
0 & & 0 \\
- & $<0.00667$ \\
0.00428 & 0.00453 \\
0.00875 & & 0.01045
\end{tabular}

38.8
c $\left\{\begin{array}{c}0 \\ <0.00614\end{array}\right.$
0.00421
0.00839

\begin{abstract}
0
\end{abstract}
0

c $\left\{\begin{array}{c}0 \\ <0.00484\end{array}\right.$

0

$-\quad<0.00525$

1
0
1

$\begin{array}{lll}0.00373 & 0.00379 & 0.00401 \\ 0.01047 & 0.01094 & 0.01313\end{array}$

45.6

\begin{tabular}{|c|c|c|}
\hline 0 & 0 & 0 \\
\hline$<<0.00353$ & - & $<0.00380$ \\
\hline 0.00375 & 0.00379 & 0.00402 \\
\hline 0.01041 & 0.01083 & 0.01300 \\
\hline
\end{tabular}

53.3

0

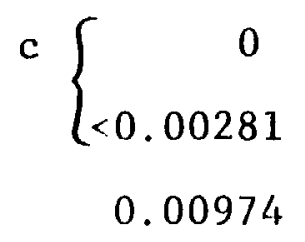

$\begin{array}{cc}- & 0 \\ - & 0 \\ - & <0.00301 \\ - & 0.01208\end{array}$

\begin{tabular}{|c|c|c|}
\hline HRXN & GLASS & MGBS \\
\hline 0.96 & 1.05 & 1.15 \\
\hline 0.9590 & 1.0448 & 1.1409 \\
\hline$>0.8832$ & $>0.9690$ & $>1.0652$ \\
\hline $0.9804 \pm 0.0054$ & 1.0719 & 1.1463 \\
\hline $1.0639 \pm 0.0092$ & 1.1624 & 1.1913 \\
\hline 0.96 & 1.05 & 1.15 \\
\hline 0.9559 & 1.0389 & 1.1326 \\
\hline$>0.8953$ & $>0.9783$ & $>1.0722$ \\
\hline $0.9850 \pm 0.0045$ & 1.0735 & 1.1444 \\
\hline $1.0317 \pm 0.0042$ & 1.1250 & 1.1484 \\
\hline 0.96 & 1.045 & 1.14 \\
\hline 0.9511 & 1.0313 & 1.1215 \\
\hline$>0.9063$ & $>0.9865$ & $>1.0772$ \\
\hline $0.9813 \pm 0.0028$ & 1.0667 & 1.1331 \\
\hline $1.0308 \pm 0.0021$ & 1.1208 & 1.1385 \\
\hline 0.96 & - & 1.14 \\
\hline 0.9451 & - & 1.1093 \\
\hline$>0.9092$ & - & $>1.0739$ \\
\hline 1.0378 & - & 1.1372 \\
\hline
\end{tabular}


Table IX (cont.)

Values of $k_{\text {eff }}$ Calculated for Critical Cylinders of Table III

$$
\mathrm{B}_{\mathrm{H}}^{2}, \mathrm{~cm}^{-2}
$$

$\underline{\mathrm{H} / 233} \mathrm{U}^{\mathrm{a}}$

$$
\text { HRXN }
$$

GLASS

MGBS

0

c $\left\{\begin{array}{c}0 \\ 0.00160\end{array}\right.$

0

0

0

-

0.00168

0.00223

0.00234

0.00222

0.00287

0.00306

d

0.00874
0.00921

0.00886

0.00950

0.00947

\begin{tabular}{|c|c|c|}
\hline HRXN & GLASS & MGBS \\
\hline 0.965 & 1.05 & 1.12 \\
\hline 0.9274 & 0.9995 & 1.0803 \\
\hline$>0.9068$ & $>0.9789$ & $>1.0603$ \\
\hline $0.0930 \pm 0.0010$ & 1.0594 & 1.1127 \\
\hline $1.0166 \pm 0.0015$ & 1.0947 & 1.1352 \\
\hline $0.9874 \pm 0.0016$ & 1.0688 & 1.0958 \\
\hline $1.0342 \pm 0.0054$ & 1.1155 & 1.1164 \\
\hline
\end{tabular}

0.01128

a.) Ratio calculated from reported concentration and from density formula. May differ slightly from reported ratio.

b.) First line for each mixture is extrapolated critical value of $k_{\text {eff }}$ for an infinite cylinder of the mixture. Uncertainty in $k_{\text {eff }}$ corresponds to reported uncertainty of $1 \%$ in measured height and uncertainty associated with extrapolation to criticality from source multiplication curves, and was calculated by HRXN-ANISN-SPBL only. Order of listing is the same as in Table III.

c.) First line enclosed by brace gives $k$ eff if cylinder which "apparently cannot be made critical at any height with the absence of a top reflector and the presence of Unichrome" were exactly critical at infinite height. Second line gives axial buckling and keff corresponding to maximum height achieved with available solution. GLASS-ANISN-SPBL values were inferred from HRXN-ANISN-SPBL.

d.) Unichrome assumed present, but may have been absent. 
Table X

\begin{tabular}{|c|c|c|c|}
\hline \multirow[b]{2}{*}{$\mathrm{H} /{ }^{233} \mathrm{U}^{2}$} & \multicolumn{3}{|c|}{$k_{\text {eff }}$} \\
\hline & HRXN-ANISN & GLASS-ANISN & MGBS-TGAN \\
\hline 1818 & 1.0014 & 0.9977 & 1.0049 \\
\hline 1898 & 1.0039 & 0.9981 & 1.0078 \\
\hline 1996 & 1.0040 & 0.9961 & 1.0085 \\
\hline 2108 & 1.0021 & 0.9918 & 1.0081 \\
\hline
\end{tabular}

a) Actually H/Fissile U. Includes trace of ${ }^{235_{U}}$. 
Table XI

Values of $k_{\text {eff }}$ Calculated for Metal Spheres of Table VI

HRXN-ANISN

\begin{tabular}{ccccccccccc} 
Case & \multicolumn{1}{c}{$\mathrm{S}_{4}$} & $\mathrm{~S}_{8}$ & $\mathrm{~S}_{16}$ & $\mathrm{~S}_{\infty}$ & $\mathrm{S}_{4}$ & $\mathrm{~S}_{8}$ & & $\mathrm{~S}_{16}$ & $\mathrm{~S}_{\infty}$ \\
1 & $1.0164 \pm 0.0010$ & 1.0074 & 1.0047 & 1.0037 & 0.9785 & 0.9696 & 0.9669 & 0.9659 \\
2 & $1.0102 \pm 0.0009$ & 1.0033 & 1.0012 & 1.0004 & 1.0217 & 1.0149 & 1.0129 & 1.0117 \\
3 & $1.0171 \pm 0.0015$ & 1.0063 & 1.0032 & 1.0021 & 1.0167 & 1.0060 & 1.0030 & 1.0019 \\
4 & $1.0175 \pm 0.0010$ & 1.0074 & 1.0045 & 1.0035 & 0.9908 & 0.9810 & 0.9782 & 0.9772 \\
5 & $1.0195 \pm 0.0016$ & 1.0091 & 1.0061 & 1.0050 & 0.9992 & 0.9891 & 0.9862 & 0.9852
\end{tabular}




\section{Table XII}

Limits for Uniform Homogeneous Aqueous Solutions of $\mathrm{UO}_{2} \mathrm{~F}_{2}$ $100 \% 233 \mathrm{U}$

\begin{tabular}{|c|c|c|c|c|c|}
\hline Parameter & Standard & HRXN-ANISN & GLASS-ANISN & MGBS-TGAN & Proposed \\
\hline Mass $\mathrm{U}, \mathrm{g}$ & 550 & 530 & 521 & 497 & 540 \\
\hline Cylinder Dia, cm & 11.5 & 10.81 & 10.50 & 10.19 & 10.5 \\
\hline Slab Thickness, cm & 3.0 & 2.47 & 2.67 & 2.82 & 2.5 \\
\hline Volume, $L$ & 3.5 & 3.09 & 2.77 & 2.52 & 2.8 \\
\hline Conc, $\mathrm{g} \mathrm{U} / \mathrm{L}$ & 10.8 & 10.83 & 10.79 & 10.73 & 10.8 \\
\hline $\mathrm{H} / \mathrm{U}$ & - & 2383 & 2392 & 2404 & 2390 \\
\hline Areal Density, $\mathrm{g} \mathrm{U} / \mathrm{cm}^{2}$ & 0.35 & 0.353 & 0.351 & 0.334 & 0.35 \\
\hline
\end{tabular}




\section{Table XIII}

\section{Limits for Uniform Homogeneous Aqueous Solutions of $\mathrm{UO}_{2}\left(\mathrm{NO}_{3}\right)_{2}$

$$
100 \% 233_{U}
$$

\begin{tabular}{|c|c|c|c|c|}
\hline Parameter & HRXN-ANISN & GLASS-ANISN & MGBS-TGAN & Proposed \\
\hline Mass $U, g$ & 543 & 536 & 523 & 550 \\
\hline Cylinder Diameter, $\mathrm{cm}$ & 11.73 & 11.69 & 11.41 & 11.7 \\
\hline Slab Thickness, cm & 3.13 & 3.41 & 3.48 & 3.1 \\
\hline Volume, & 3.74 & 3.61 & 3.36 & 3.6 \\
\hline Conc, g U/ & 10.86 & 10.82 & 10.76 & 10.8 \\
\hline $\mathrm{H} / \mathrm{U}$ & 2371 & 2379 & 2393 & 2390 \\
\hline Areal Density, $\mathrm{g} \mathrm{U} / \mathrm{cm}^{2}$ & 0.357 & 0.355 & 0.339 & 0.350 \\
\hline
\end{tabular}


Table XIV

Limits Calculated for Metal and Dry Oxide ${ }^{a}$

$100 \% 233_{\mathrm{U}}$

\begin{tabular}{|c|c|c|c|c|c|}
\hline Material & Parameter & HRXN-ANISN & GLASS-ANISN & Standard & Proposed \\
\hline \multirow[t]{3}{*}{ Metal } & M & 6.95 & 6.05 & 6.7 & 6.0 \\
\hline & $D$ & 4.90 & 4.53 & 4.6 & 4.5 \\
\hline & $\mathrm{T}$ & 0.61 & 0.38 & 0.54 & 0.38 \\
\hline \multirow[t]{4}{*}{$\mathrm{UO}_{2}$} & $M$ & 13.05 & 10.90 & & 10.9 \\
\hline & MO & 14.84 & 12.39 & & 12.4 \\
\hline & $D$ & 7.89 & 7.20 & & 7.2 \\
\hline & $\mathrm{T}$ & 1.28 & 0.80 & & 0.80 \\
\hline \multirow[t]{4}{*}{$\mathrm{U}_{3} \mathrm{O}_{8}$} & M & 18.57 & 15.10 & & 15.1 \\
\hline & MO & 21.97 & 17.86 & & 17.8 \\
\hline & D & 9.94 & 8.98 & & 9.0 \\
\hline & $\mathrm{T}$ & 1.79 & 1.12 & & 1.1 \\
\hline \multirow[t]{4}{*}{$\mathrm{UO}_{3}$} & M & 21.89 & 17.56 & & 17.5 \\
\hline & MO & 26.40 & 21.17 & & 21.1 \\
\hline & $\mathrm{D}$ & 11.07 & 9.95 & & 9.9 \\
\hline & $\mathrm{T}$ & 2.09 & 1.31 & & 1.3 \\
\hline
\end{tabular}

a) Densities of $\mathrm{U}, \mathrm{UO}_{2}, \mathrm{U}_{3} \mathrm{O}_{8}$, and $\mathrm{UO}_{3}$ may not exceed $18.65,10.76,8.15$, and $7.16 \mathrm{~g} / \mathrm{cm}^{3}$.

b) $M=$ Mass of $U$ in $\mathrm{kg}$. MO = Mass of uranium oxide in $\mathrm{kg}$.

$\mathrm{D}=$ Cylinder diameter in $\mathrm{cm}$. $\mathrm{T}=\mathrm{Slab}$ thickness in $\mathrm{cm}$. 
Table XV

Limits Calculated for Moist ${ }^{a}$ Oxide

\begin{tabular}{|c|c|c|c|c|c|}
\hline Density $^{b}$ & Oxide & Parameter $^{c}$ & HRXN-ANISN & GLASS-ANISN & Proposed \\
\hline \multirow[t]{12}{*}{ Full } & $\mathrm{UO}_{2}$ & M & 13.00 & 10.15 & 10.1 \\
\hline & & MO & 15.01 & 11.72 & 11.7 \\
\hline & & D & 8.35 & 7.44 & 7.2 \\
\hline & & $\mathrm{T}$ & 1.42 & 0.87 & 0.80 \\
\hline & $\mathrm{U}_{3} \mathrm{O}_{8}$ & $-M$ & 17.62 & 13.38 & 13.4 \\
\hline & & MO & 21.17 & 16.07 & 16.0 \\
\hline & & $\mathrm{D}$ & 10.22 & 9.01 & 9.0 \\
\hline & & $\mathrm{T}$ & 1.90 & 1.17 & 1.1 \\
\hline & $\mathrm{UO}_{3}$ & M & 20.39 & 15.26 & 15.2 \\
\hline & & MO & 24.96 & 18.69 & 18.7 \\
\hline & & $\mathrm{D}$ & 11.26 & 9.88 & 9.9 \\
\hline & & $T$ & 2.19 & 1.34 & 1.3 \\
\hline \multirow[t]{12}{*}{$\mathrm{Half} \mathrm{f}^{\mathrm{d}}$} & $\mathrm{UO}_{2}$ & M & 32.69 & 23.40 & 23.4 \\
\hline & & MO & 37.75 & 27.02 & 27.0 \\
\hline & & $\mathrm{D}$ & 14.26 & 12.31 & 11.9 \\
\hline & & $T$ & 2.84 & 1.74 & 1.6 \\
\hline & $\mathrm{U}_{3} \mathrm{O}_{8}$ & $M$ & 44.06 & 30.50 & 30.5 \\
\hline & & MO & 52.92 & 36.64 & 36.6 \\
\hline & & D & 17.48 & 14.91 & 14.8 \\
\hline & & $\mathrm{T}$ & 3.80 & 2.34 & 2.2 \\
\hline & $\mathrm{UO}_{3}$ & M & 50.93 & 34.68 & 34.7 \\
\hline & & MO & 62.35 & 42.46 & 42.4 \\
\hline & & $D$ & 19.28 & 16.36 & 16.3 \\
\hline & & $\mathrm{T}$ & 4.37 & 2.68 & 2.6 \\
\hline
\end{tabular}


Table XV (cont.)

a) Oxide contains $1.5 \% \mathrm{H}_{2} \mathrm{O}$.

b) Full density of moist oxide is based on the assumption that the volume of moist oxide is the sum of the volume of dry oxide at physical density $\left(10.76,8.15\right.$, and $7.16 \mathrm{~g} / \mathrm{cm}^{3}$, respectively, for $\mathrm{UO}_{2}, \mathrm{U}_{3} \mathrm{O}_{8}$, and $\left.\mathrm{UO}_{3}\right)$ and the volume of water at $20^{\circ}$ with density $0.99823 \mathrm{~g} / \mathrm{cm}^{3}$.

c) $\mathrm{M}=$ Mass of $\mathrm{U}$ in $\mathrm{kg}, \mathrm{MO}=$ Mass of moist oxide in $\mathrm{kg}, \mathrm{D}=$ cylinder diameter in $\mathrm{cm}, \mathrm{T}=\mathrm{slab}$ thickness in $\mathrm{cm}$.

d) Densities of oxide and water are halved, i.e. moist oxide contains $50 \%$ voids. 
Table A.I

Two Group Cross Sections

\begin{tabular}{|c|c|c|c|c|c|c|}
\hline Material & Group & $\Sigma_{2}$ & $v \Sigma_{f}$ & $\Sigma$ & $\sum_{g \rightarrow g}$ & $\sum_{g \rightarrow g+1}$ \\
\hline \multirow[t]{2}{*}{ U Solution } & 1 & 0.020794 & 0.044029 & 0.267053 & 0.222033 & 0.024226 \\
\hline & 2 & 0.362821 & 0.800351 & 1.39704 & 1.03421 & 0 \\
\hline \multirow{2}{*}{$\mathrm{H}_{2} \mathrm{O}$} & 1 & 0.000458 & 0 & 0.255747 & 0.204324 & 0.050965 \\
\hline & 2 & 0.018972 & 0 & 2.23097 & 2.21200 & 0 \\
\hline \multirow[t]{2}{*}{ Al } & 1 & 0.000419 & 0 & 0.135803 & 0.135163 & 0.000221 \\
\hline & 2 & 0.011993 & 0 & 0.089297 & 0.077304 & 0 \\
\hline
\end{tabular}


Table A. 2

Critical Benchmark Cylinders

\begin{tabular}{|c|c|c|c|}
\hline$\underline{\mathrm{H} / \mathrm{D}}$ & Wall & $\mathrm{D}(\mathrm{cm})$ & $\mathrm{H}(\mathrm{cm})$ \\
\hline \multirow[t]{2}{*}{$0^{a}$} & None & $\infty$ & 2.73126 \\
\hline & $0.16 \mathrm{~cm} \mathrm{~A} 1$ & $\infty$ & 2.75136 \\
\hline 0.25 & None & 25.9620 & 6.4905 \\
\hline \multirow[t]{2}{*}{0.50} & None & 19.1352 & 9.5676 \\
\hline & $0.16 \mathrm{~cm} \mathrm{~A} 1$ & 19.2670 & 9.6335 \\
\hline 1.0 & None & 14.9304 & 14.9304 \\
\hline \multirow[t]{2}{*}{2.0} & None & 12.4237 & 24.8474 \\
\hline & $0.16 \mathrm{~cm} \mathrm{AI}$ & 12.5212 & 25.0424 \\
\hline 4.0 & None & 11.0869 & 44.3476 \\
\hline \multirow[t]{2}{*}{$\infty$} & None & 10.2008 & $\infty$ \\
\hline & $0.16 \mathrm{~cm} \mathrm{Al}$ & 10.2496 & $\infty$ \\
\hline
\end{tabular}

a) Calculated by ANISN 
Table A. 3

Application of ANISN-SPBL to Benchmarks

\begin{tabular}{|c|c|c|c|c|c|}
\hline$\underline{H / D}$ & Wa1I & $\mathrm{BH}^{2}, \mathrm{~cm}^{-2}$ & $\mathbf{k}_{D}$ & $\mathrm{k}_{\mathrm{H}}$ & $k_{e f f}$ \\
\hline \multirow[t]{2}{*}{0} & None & 0.04698 & 2.1644 & 1.0000 & 1.0000 \\
\hline & $\mathrm{Al}$ & 0.04698 & 2.1644 & 1.0000 & 1.0000 \\
\hline 0.25 & None & 0.02604 & 1.5545 & 1.2903 & 1.0705 \\
\hline \multirow[t]{2}{*}{0.5} & None & 0.01859 & 1.3722 & 1.4494 & 1.0719 \\
\hline & $\mathrm{Al}$ & 0.01839 & 1.3736 & 1.4544 & 1.0767 \\
\hline 1.0 & None & 0.01182 & 1. 2212 & 1.6402 & 1.0570 \\
\hline \multirow[t]{2}{*}{2.0} & None & 0.00641 & 1.1118 & 1.8403 & 1.0340 \\
\hline & AI & 0.00631 & 1.1146 & 1.8445 & 1.0374 \\
\hline 4.0 & None & 0.00284 & 1.0462 & 2.0066 & 1.0148 \\
\hline \multirow[t]{2}{*}{$\infty$} & None & 0 & 0.9995 & 2.1644 & 0.9995 \\
\hline & $\mathrm{AI}$ & 0 & 0.9994 & 2.1644 & 0.9994 \\
\hline
\end{tabular}


Table A. 4

ANISN-SPBL with Hansen-Roach Cross Sections Applied to Benchmarks

H/D

$\mathrm{BH}^{2}, \mathrm{~cm}^{-2}$

$\mathrm{kD}$

$\mathrm{k}_{\mathrm{H}}$

$k_{e f f}$

0.5

0.01924

1.2955

1.3768

0.9604

1.0

0.01213

1. 1282

1.5762

0.9429

2.0

0.00651

1.0043

1. 7757

0.9159

4.0

0.00286

0.9292

1.9337

0.8935

$\infty$

0

0.8756

0.8756 


\section{Table A. 5}

\section{Analysis of Benchmarks by Critical Transverse Buckling Implemented by ANISN}

\begin{tabular}{|c|c|c|c|}
\hline $\mathrm{H} / \mathrm{D}$ & Wa11 & $\mathrm{BH}^{2 \mathrm{a}}$ & $k_{e f f}$ \\
\hline \multirow[t]{2}{*}{0} & None & 0.04698 & 1.0000 \\
\hline & $\mathrm{Al}$ & 0.04698 & 1.0000 \\
\hline 0.25 & None & 0.03065 & 0.9982 \\
\hline \multirow[t]{2}{*}{0.50} & None & 0.02261 & 0.9980 \\
\hline & AI & 0.02363 & 0.9813 \\
\hline 1.00 & None & 0.01440 & 0.9988 \\
\hline \multirow[t]{2}{*}{2.00} & None & 0.00756 & 1.0001 \\
\hline & $\mathrm{AI}$ & 0.00785 & 0.9937 \\
\hline 4.00 & None & 0.00318 & 1.0003 \\
\hline \multirow[t]{2}{*}{$\infty$} & None & 0 & 0.9995 \\
\hline & $\mathrm{AI}$ & 0 & 0.9994 \\
\hline
\end{tabular}

a) $\mathrm{BH}^{2}=$ Calculated critical buckling - calculated critical radial buckling. 
Table A. 6

Analysis of Benchmarks by TGAN

\begin{tabular}{|c|c|c|c|}
\hline \multirow[b]{2}{*}{$\underline{\mathrm{H} / \mathrm{D}}$} & \multirow[b]{2}{*}{ Wall } & \multicolumn{2}{|c|}{$k_{\text {eff }}$} \\
\hline & & GLASS & MGBS \\
\hline \multirow[t]{2}{*}{0} & None & 1.0098 & 1.0657 \\
\hline & $\mathrm{A} 1$ & 1.0093 & 1.0593 \\
\hline \multirow[t]{2}{*}{0.50} & None & 0.9964 & 1.0726 \\
\hline & $\mathrm{A} 1$ & 0.9784 & 1.0498 \\
\hline 1.00 & None & 0.9968 & 1.0729 \\
\hline \multirow[t]{2}{*}{2.00} & None & 0.9990 & 1.0722 \\
\hline & $\mathrm{Al}$ & 0.9922 & 1.0605 \\
\hline \multirow[t]{3}{*}{4.00} & None & 1.0008 & 1.0712 \\
\hline & None & 1.0014 & 1.0699 \\
\hline & Al & 1.0017 & 1.0648 \\
\hline
\end{tabular}




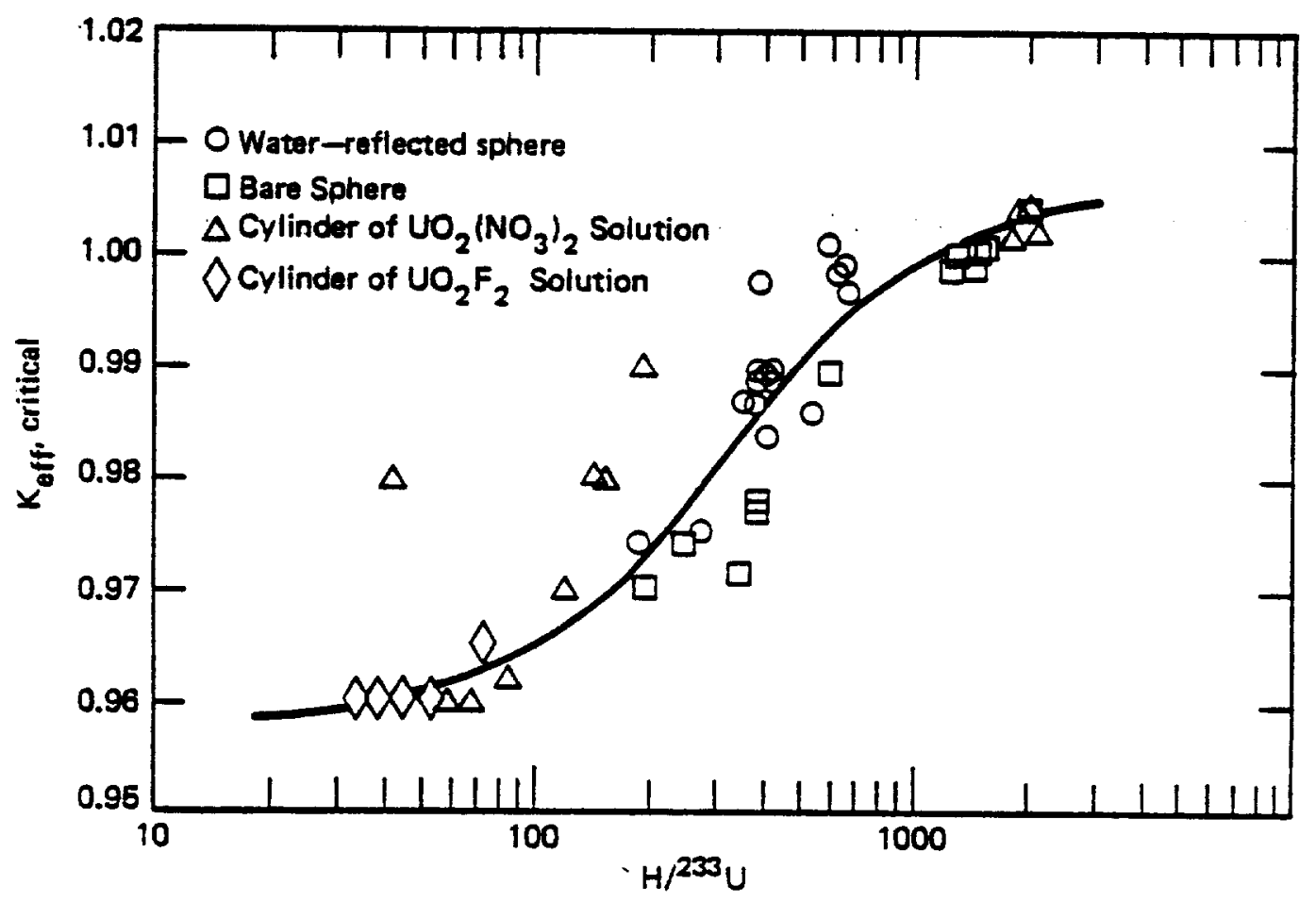

Figure 1. keff Calculated by HRXN-ANISN ( $\left.S_{\infty}\right)$ for Critical Configurations. The line is an "eyeball" fit. 


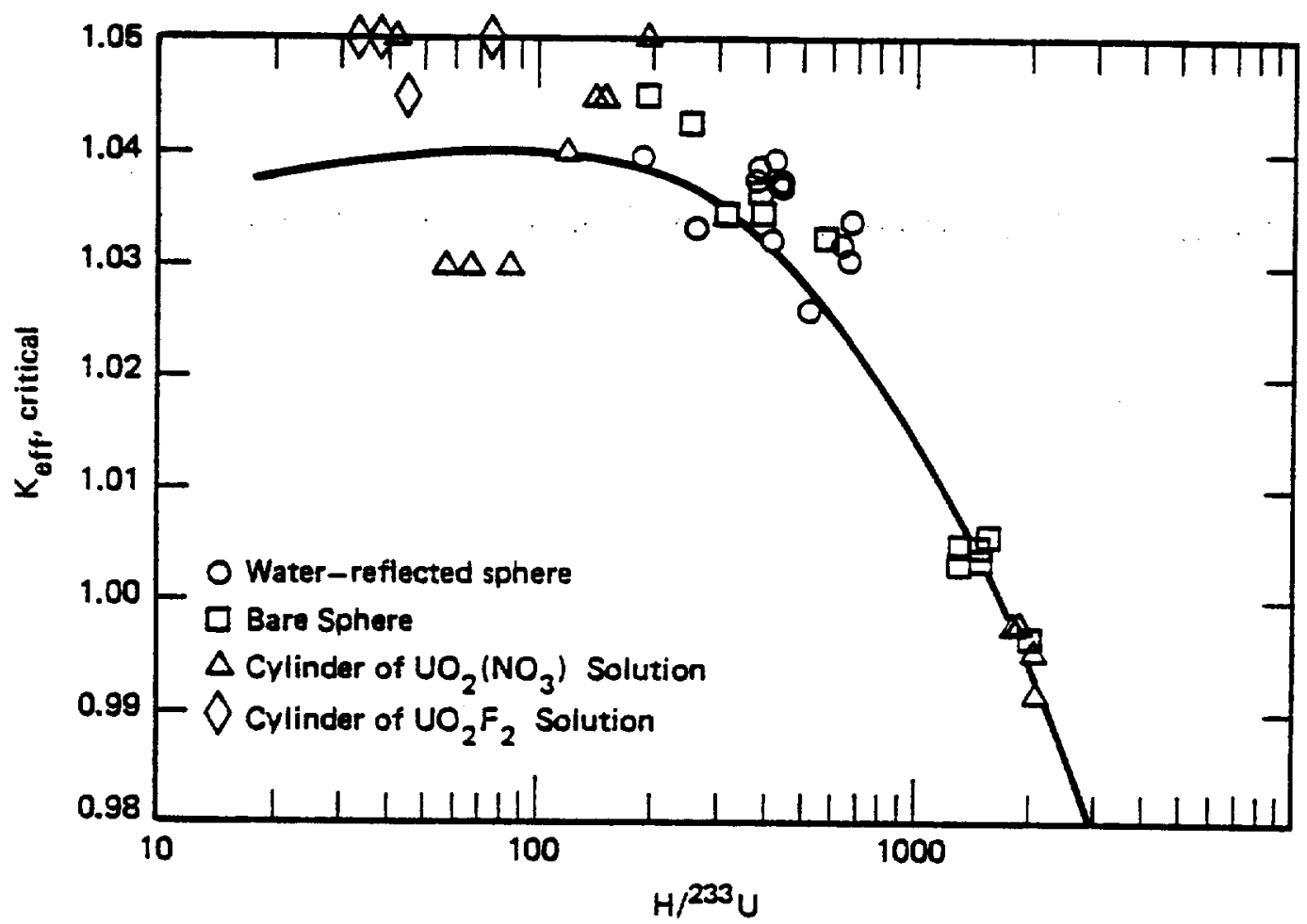

Figure 2. keff Calculated by GLASS-ANISN $\left(S_{\infty}\right)$ for Critical Configurations. The line is an "eyeball" fit. 


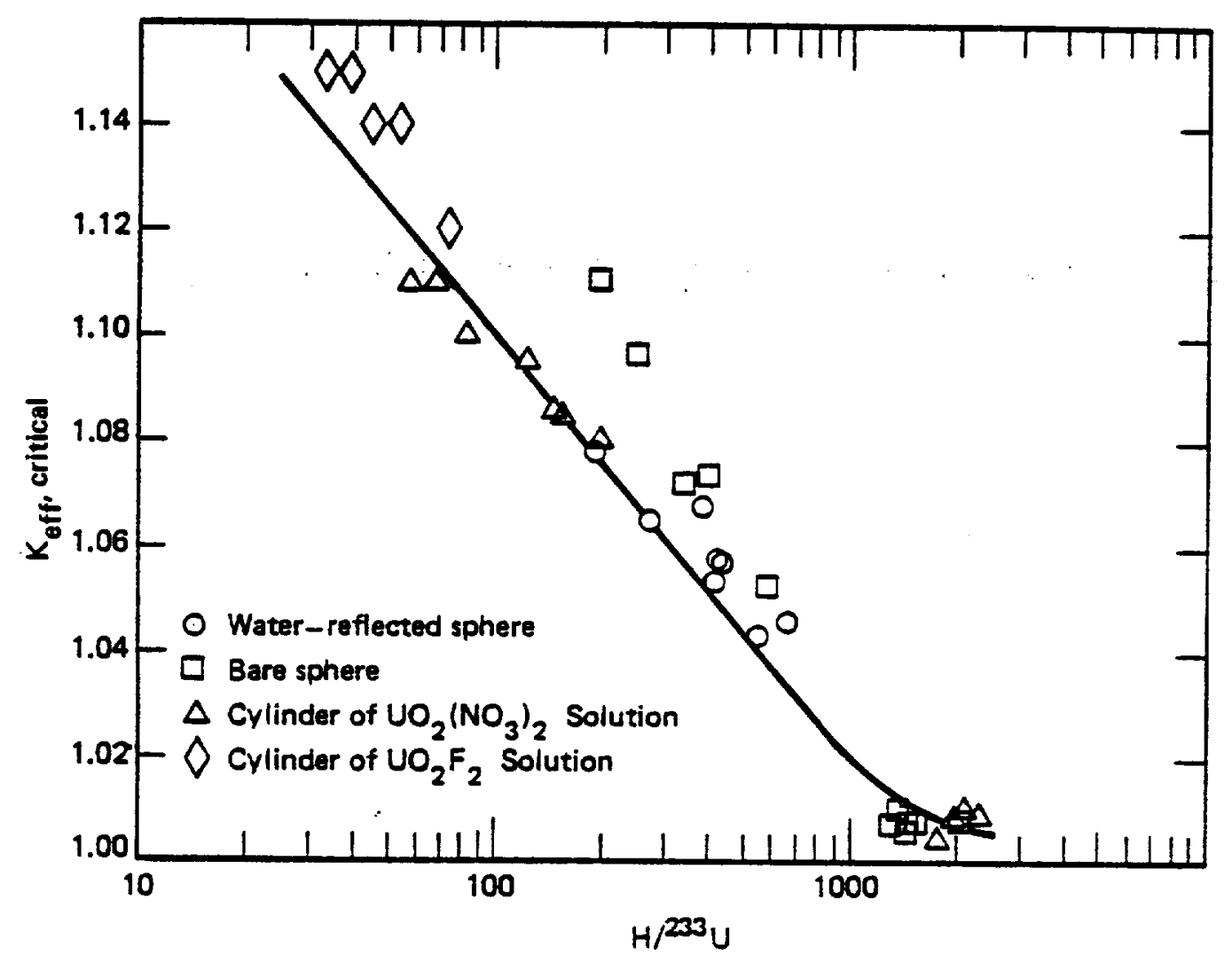

Figure 3. keff Calculated by MGBS-TGAN for Critical Configurations. The line is an "eyeball" fit. 


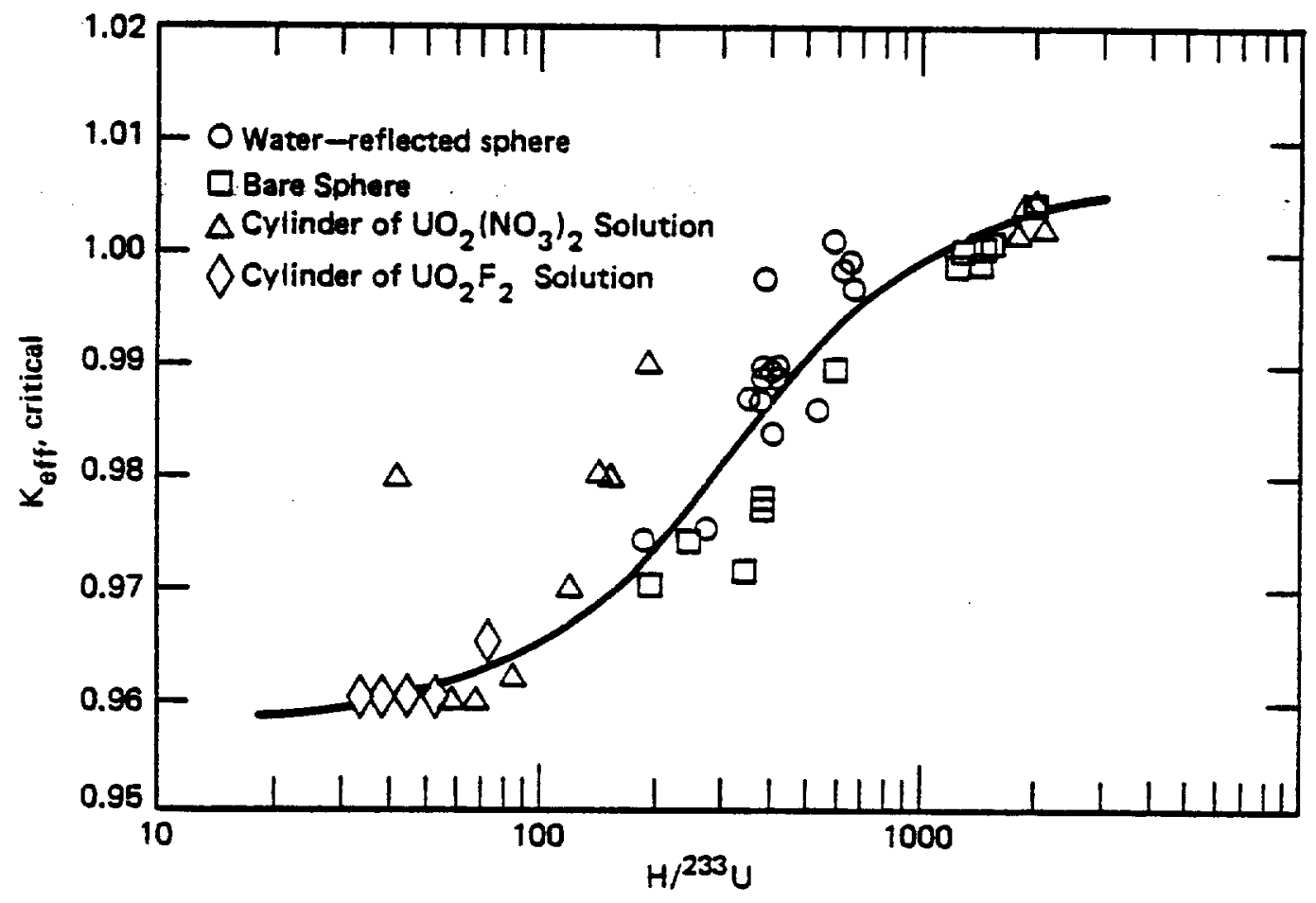

Figure 1. keff Calculated by HRXN-ANISN $\left(S_{\infty}\right)$ for Critical Configurations. The line is an "eyeball" fit. 


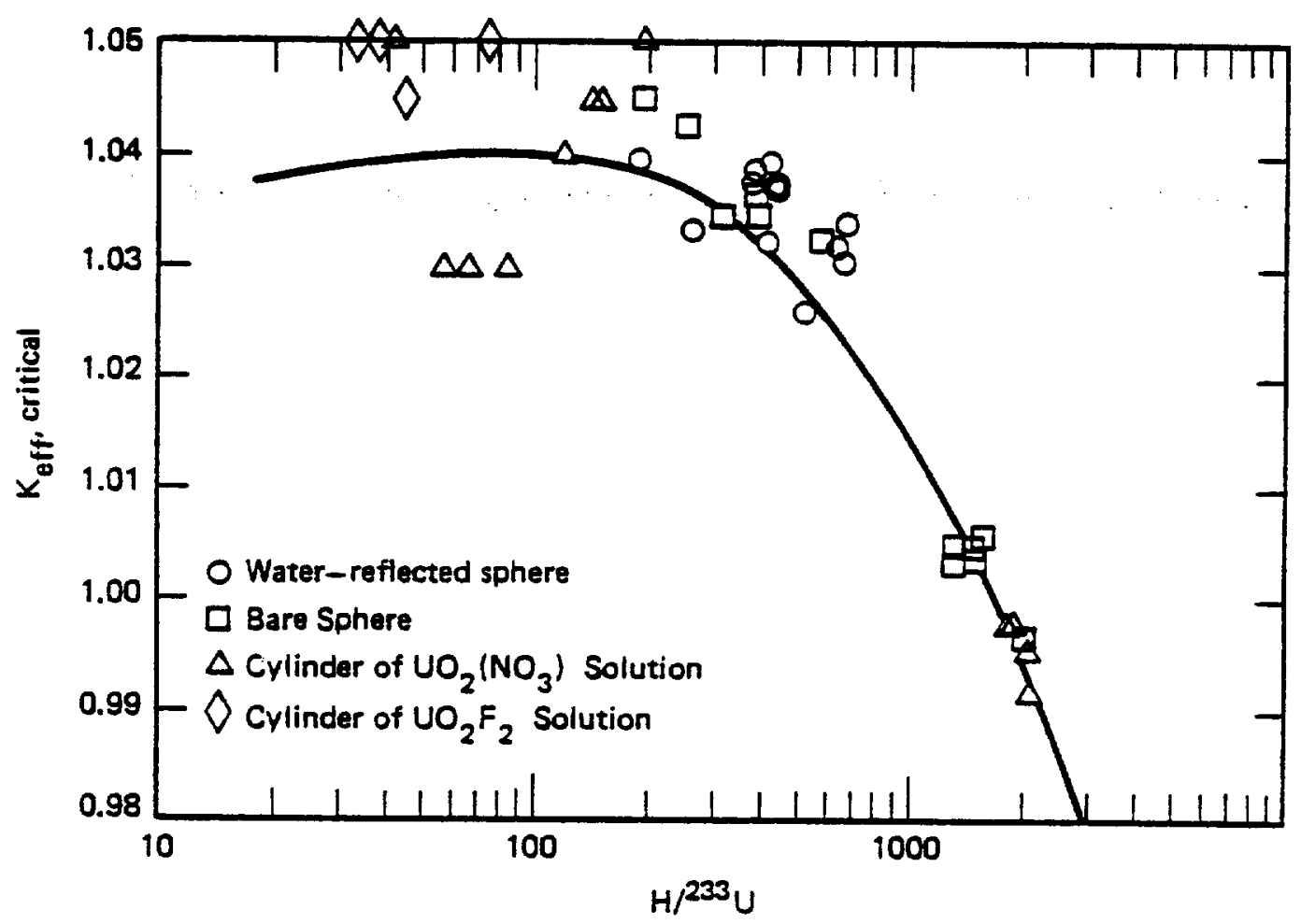

Figure 2. keff Calculated by GLASS-ANISN $\left(S_{\infty}\right)$ for Critical Configurations. The line is an "eyeball" fit. 


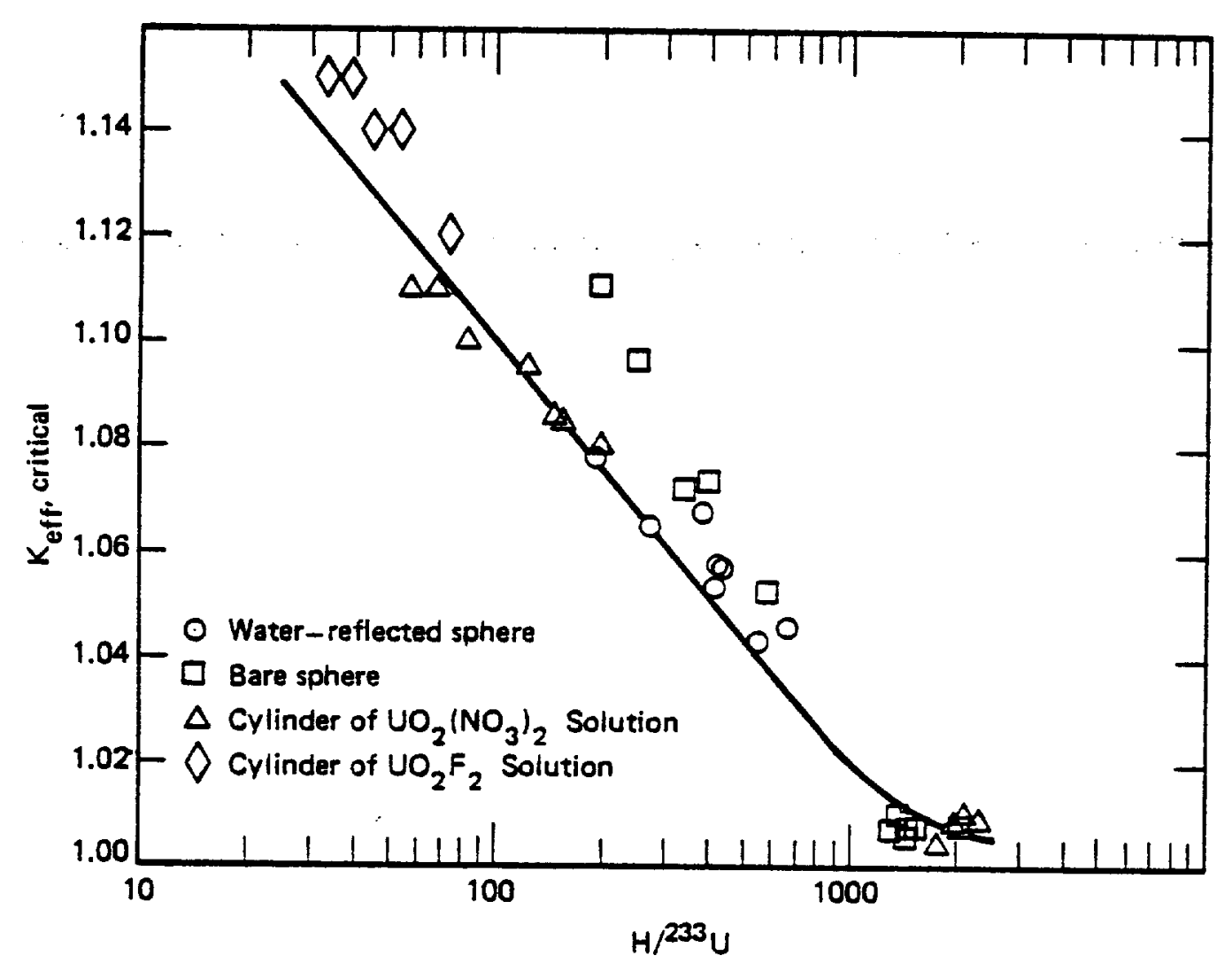

Figure 3. keff Calculated by MGBS-TGAN for Critical Configurations. The line is an "eyeball" fit. 


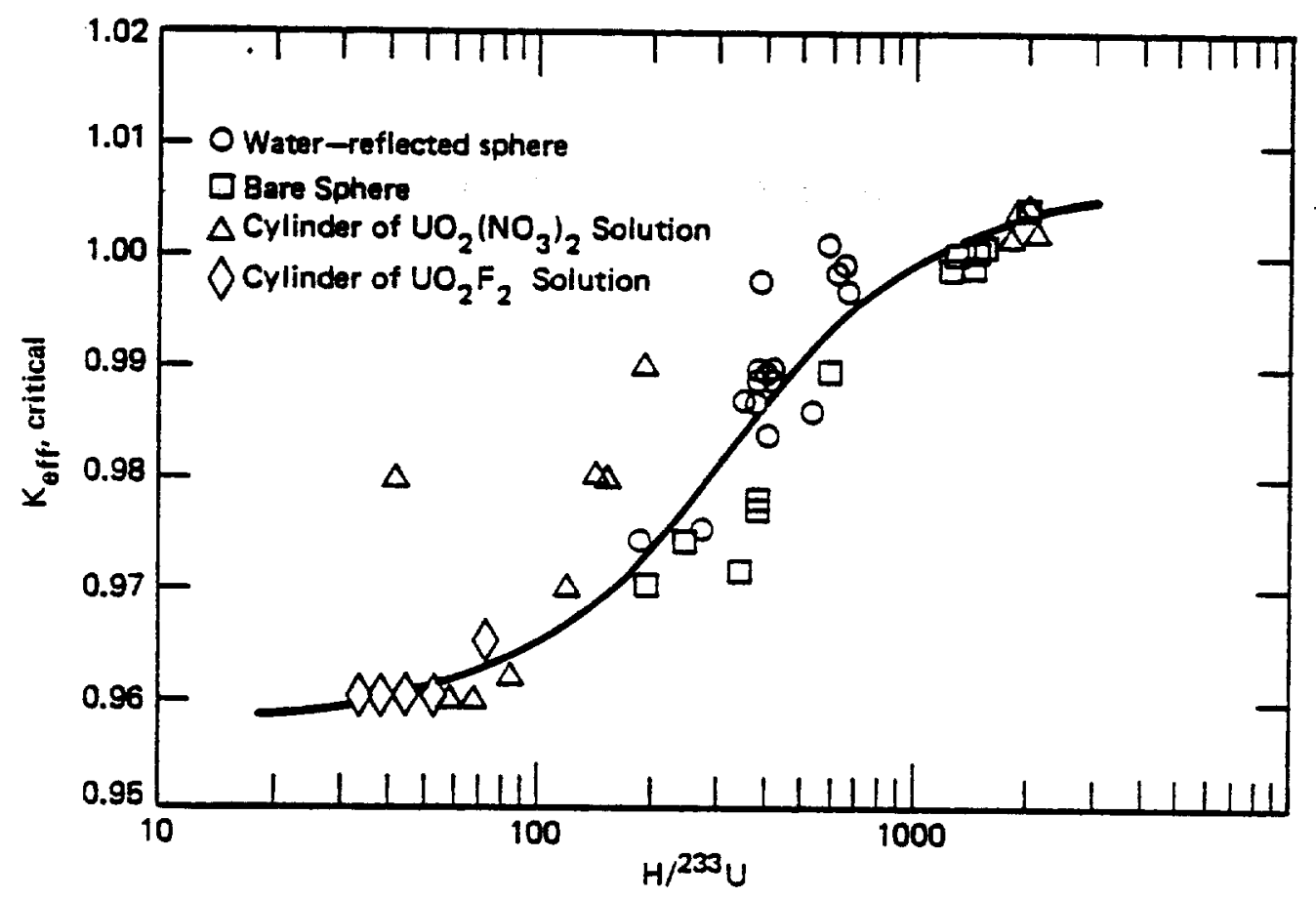

Figure 1. keff Calculated by HRXN-ANISN $\left(S_{\infty}\right)$ for Critical Configurations. The line is an "eyeball" fit. 


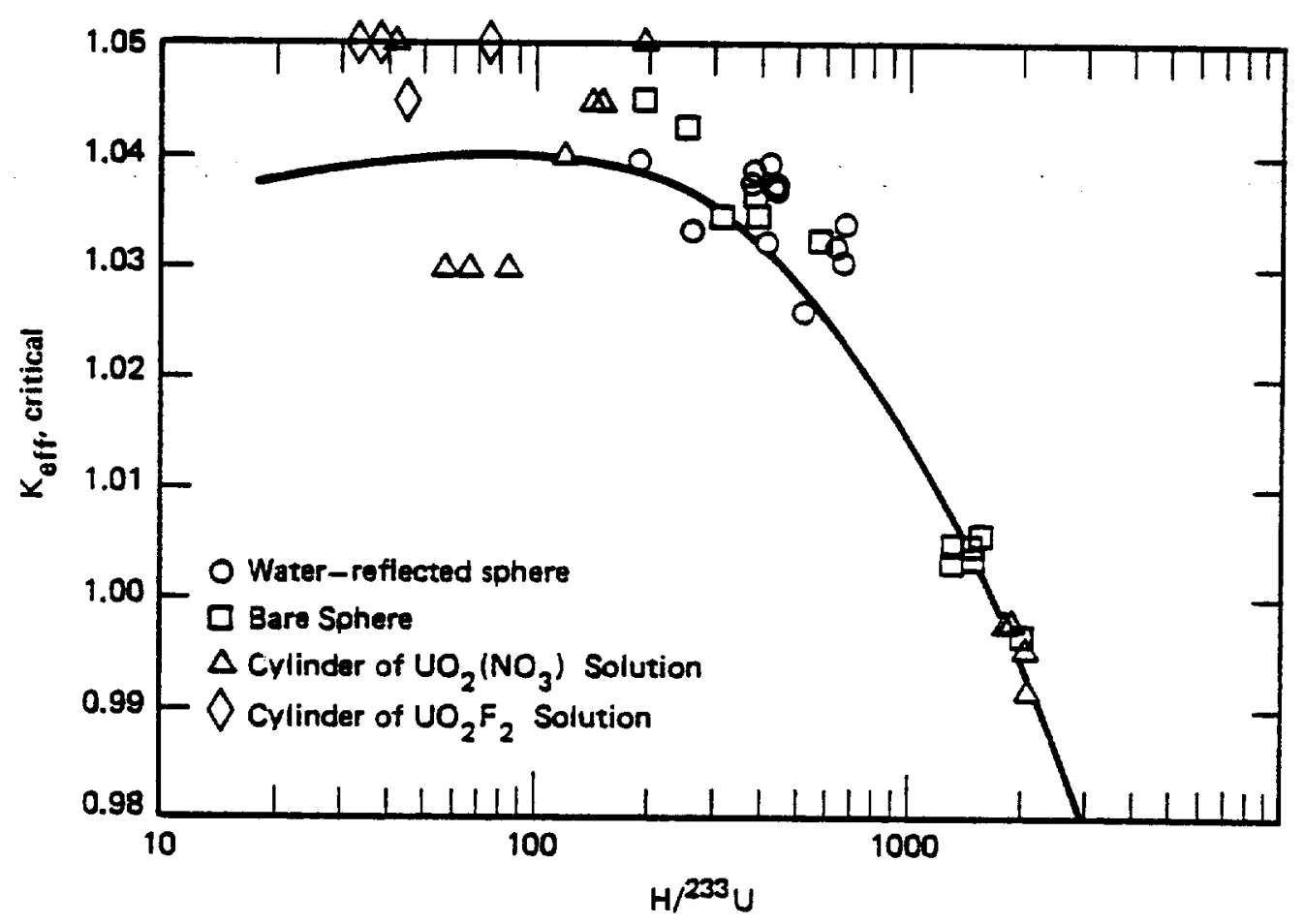

Figure 2. keff Calculated by GLASS-ANISN $\left(S_{\infty}\right)$ for Critical Configurations. The line is an "eyeball" fit. 


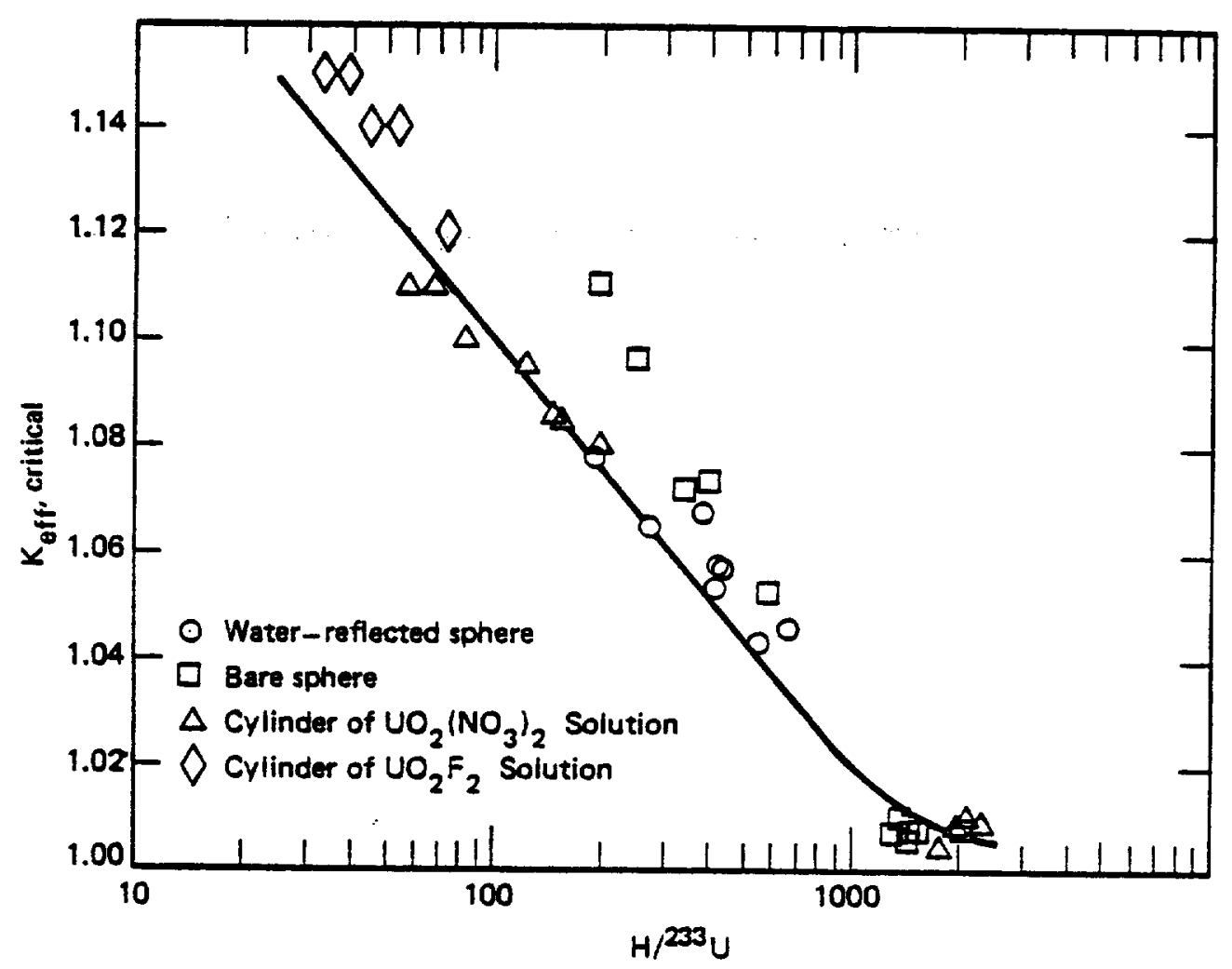

Figure 3. keff Calculated by MGBS-TGAN for Critical Configurations. The line is an "eyeball" fit. 


\author{
CC: J. M. Gaver, DOE-SR \\ S. Mirshak - \\ J. R. Hilley, SRL \\ M. R. Buckner \\ H. K. Clark \\ TIS File \\ October 9, 1981
}

\title{
TO DISTRIBUTION
}

Attached is a copy of the following:

DP-MS-81-67, "Subcritical Limits for ${ }^{233}$ U Systems" by H. K. Clark.

This paper is proposed for publication in Nuclear Science and Engineering.

If there are comments about its release, notify the TIS office within 14 days (Ext. 3598).

For any technical clarification, we suggest you call:

M. R. Buckner, Research Manager

Nuclear Physics Division

Savannah River Laboratory 